\title{
Synthesis, structure and electrochemistry of Fischer alkoxy- and aminocarbene complexes of tungsten: The use of DFT to predict and understand oxidation and reduction potentials
}

\author{
Marilé Landman, ${ }^{\mathrm{a} *}$ René Pretorius, ${ }^{a}$ Blenerhassitt E. Buitendach, ${ }^{\mathrm{b}}$ Petrus H. van Rooyen ${ }^{\mathrm{a}}$ and Jeanet \\ Conradie $^{\mathrm{b}_{*} \ddagger}$ \\ ${ }^{a}$ Department of Chemistry, University of Pretoria, Private Bag X20, Hatfield, 0028, South Africa. Tel: 27-12-4202527 Fax: \\ 27-12-4204687 \\ ${ }^{\mathrm{b}}$ Department of Chemistry, PO Box 339, University of the Free State, Bloemfontein, 9300, South Africa. Tel: 27-51- \\ 4012194, Fax: 27-51-4446384
}

Fischer alkoxycarbene complexes, Fischer aminocarbene complexes, Ethylene diamine, Electrochemistry, DFT calculations

Supporting Information Placeholder

\begin{abstract}
Reactions of Fischer alkoxycarbene complexes $\left[\mathrm{W}(\mathrm{CO})_{5}\{\mathrm{C}(\mathrm{OEt}) \mathrm{Ar}\}\right], \mathrm{Ar}=$ thienyl (1) or furyl (2), with ethylene diamine lead to the formation of two different reaction products: an aminolysis product ( $\mathbf{5}$ or $\mathbf{6}$ ) where the ethoxy substituent of the carbene ligand is replaced by the ethylene diamine moiety, as well as a chelated product where aminolysis and substitution of one carbonyl ligand had taken place, yielding $\mathbf{7}$ or $\mathbf{8}$. Aminolysis of $\mathbf{1}$ and $\mathbf{2}$ with cyclohexyl amine (CHA) produced the aminocarbene complexes $3(\mathrm{Ar}=$ thienyl $)$ and $\mathbf{4}(\mathrm{Ar}=$ furyl $)$. Complexes 1-8 are electrochemically investigated by means of cyclic voltammetry. The relative shifts in the oxidation and reduction potentials are discussed and related to density functional theory (DFT) calculated energies. DFT calculations further show that the oxidation center is located on the metal and the carbonyl groups, while the reduction center is localized on the carbene moiety and is strongly influenced by the electronic properties of its substituents. Crystal structures of 1-4, 6 and 8 are reported.
\end{abstract}

\section{INTRODUCTION}

Several modifications of classical carbonyl derived carbenes have been attempted. ${ }^{1,2,3}$ Both the carbene substituents and the ligand sphere of the metal can be altered, allowing modulation of both the reactivity and the stability of these complexes.

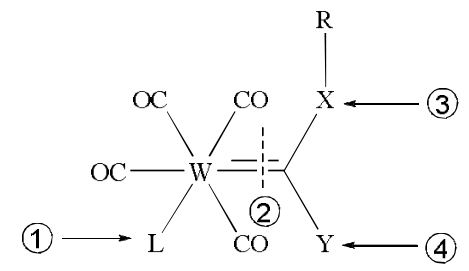

$\mathrm{L}=$ Ligand; $\mathrm{X}=$ Heteroatom; $\mathrm{Y}=$ Substituent;

$\mathrm{R}=$ Alkyl or Aryl Group

Figure 1. Potential sites of Fischer carbene modification
- Fischer carbenes are generally characterised by the presence of at least one heteratom substituent on the carbene carbon, ${ }^{4,5,6}$ which is represented by $\mathrm{X}$ in Figure 1. $\mathrm{X}$ is generally an $\mathrm{O}, \mathrm{N}$, or $\mathrm{S}$ atom, since these heteroatoms have lone pairs which can stabilize the carbene by $\pi$-donation. The substituents found in position $\mathrm{Y}$ range from alkyl and aryl derivatives to heteroatoms. Modifications of the ligand sphere of the metal can also be performed (reaction 1, Figure 1). However, to maintain the classical low oxidation state of Fischer carbenes, the $\mathrm{CO}$ ligands should be substituted with neutral ligands. ${ }^{7,8}$ Fischer carbenes are known to be electrophilic and are thus susceptible to nucleophilic attack on the carbene carbon. ${ }^{4,7}$ Alkoxycarbenes are readily altered in this manner, which leads to the formation of amino, thio- and aryl-carbene complexes, respectively (reaction 3, Figure 1). ${ }^{10}$ Of these modifications, aminolysis has been used most extensively ${ }^{11}$ because of the relative ease of the reaction and the increased stability of the products. Aminocarbenes were synthesised not long after the first stable alkoxycarbene. ${ }^{12}$ Aminolysis of alkoxy Fischer carbenes occurs in a similar fashion to the reaction of an ester with an amine, and is base catalysed. ${ }^{13}$ Alternative methods for the production of aminocarbenes include the Hegedus synthesis ${ }^{14}$ and nucleophilic attack of isocyanide metal complexes ${ }^{3}$ as well as nucleophilic attack of a carbonyl group with an amino lithium salt, for example LDA. ${ }^{15}$ In a recent density functional theory (DFT) study by Solá, ${ }^{11}$ the mechanism of aminolysis was found to proceed via a zwitterionic intermediate that was generated by the nucleophilic attack at the carbene center. Applications of aminocarbene complexes include polymer-bound amino chromium Fischer carbene complexes ${ }^{16}$ and aminocarbenes are used in the Pauson-Khand cyclization reaction. ${ }^{17}$ The activation of photochemical inert tungsten carbene complexes was achieved by modification of an aminocarbene's ligand sphere. ${ }^{18}$ In this study the Y substituent was represented by either a furyl ring or a thienyl ring (position 4, Figure 1). In a recent report by Ludvík et $a l .{ }^{19}$ on the electrochemical properties of chromium( $(0)$ aminocarbene complexes with heteroaryl carbene 
substituents, it was found that neither a change in heteroaryl, nor a different position of its attachment (2position vs. 3-position) had a marked influence on the oxidation behaviour, indicating limited metal-carbene communication. For the reduction, the thienyl and furyl heterocyles showed similar behaviour, but the complexes with heteroaryls attached at the 2-position were more easily reduced than those at the 3 -position.

$\bullet$

- The design of new carbene systems requires an understanding of their redox abilities, as well as knowledge of the relationship between structure and chemical properties. We therefore present with this contribution structural and electrochemical studies of a series of alkoxyand aminocarbene complexes of tungsten $(0)$. The influence of different heteroatoms $(\mathrm{O} v s . \mathrm{N})$, ligands (chelates vs. non-chelates) and substituents (thienyl vs. furyl) on the oxidation and reduction potentials of these tungsten( 0 ) complexes is expressed quantitatively, and correlated with electrochemical data by means of DFT calculated energies.

\section{RESULTS AND DISCUSSION}

\section{Synthesis of carbene complexes}

- Fischer carbenes can be synthesised by two methods, namely the original "Fischer route" and the HegedusSemmelhack synthesis. ${ }^{20,21,14}$ The classical "Fischer route" is still the most popular and makes use of the addition of lithium salts of organic substituents to the metal carbonyl reagent. This is followed by O-alkylation using hard alkylation agents, thus yielding alkoxycarbenes. The Fischer method finds its greatest limitation in the availability of the organolithium reagent. The Hegedus-Semmelhack synthesis offers an alternative to the Fischer route when such limitations are found. For the synthesis of heteroaryl carbenes, the "Fischer route" is most often used. ${ }^{22,23,24}$ This method was thus used for the synthesis of the known ethoxy Fischer carbene complexes $\mathbf{1}^{25}$ and $\mathbf{2}^{26}$, which were the precursors to the novel complexes 3-8. Monocarbene complexes 1 and 2 were prepared by deprotonation of the corresponding heteroaryl ring at low temperatures in tetrahydrofuran (THF), metallation and finally alkylation with triethyloxonium tetrafluoroborate in dichloromethane (DCM). Both products were bright red.

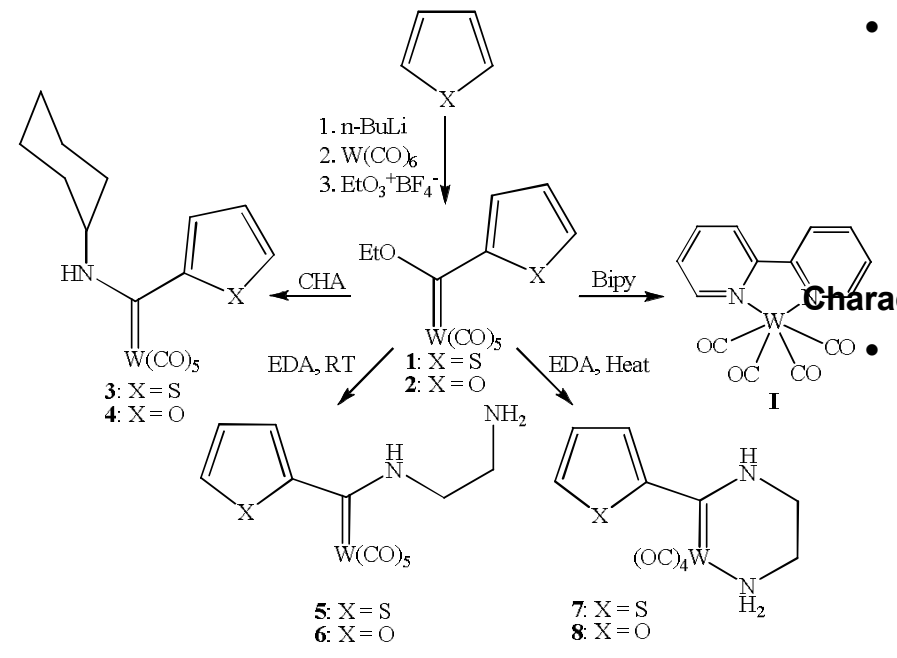

Scheme 1. Synthesis of aminocarbene complexes

$\bullet$

- When 1 or $\mathbf{2}$ was reacted with 2,2'-bipyridine (bipy), no substituted Fischer carbene complexes could be isolated (Scheme 1). The known compound [W(CO) $)_{4}($ bipy) $], \mathbf{I}^{27}$ was formed exclusively in each case. Carbene ligand substitution (reaction 2, Figure 1) in this instance dominated due to electronic reasons. Reaction of the alkoxycarbene complexes with cyclohexyl amine (CHA) resulted in the substitution of the alkoxy group by an amine substituent (reaction 3, Figure 1). CHA is a sterically demanding group, and very few examples of aminocarbene complexes with this substituent are found in literature. ${ }^{28}$ Ethylene diamine (EDA) has two nitrogen groups, which can both be used for aminolysis (reaction 3, figure 1), thereby allowing two complexes to be linked, ${ }^{29}$ or if the reaction conditions are controlled correctly, a chelate may be formed (reactions 1 and 3, Figure 1). Aminolysis of complexes 1 and 2 with ethylene diamine, followed by the formation of an amino chelate was investigated in this study. This allowed for comparison of the effect of $\sigma$-donors (amines) and $\sigma$ donor, $\pi$-acceptors (carbonyls) on the properties of the carbene complexes.

- Complexes 3, 4, 5 and 6 were synthesised using classical aminolysis methods. ${ }^{4,70}$ The required amine was added to a solution of the ethoxy monocarbene complexes (1 and 2) at room temperature. For the novel complexes $\mathbf{3}$ and $\mathbf{4}$ diethyl ether or THF was used as solvent. Generally, ethers are the preferred solvents for aminolysis. This is due to the increased reaction rate because of the stabilisation of the reaction intermediates. DCM was used instead of diethyl ether for the synthesis of complexes 5 and $\mathbf{6}$. Purification of these complexes was found to be complicated when ethers were used as solvents. It is possible that the solvent molecules became trapped due to hydrogen bonding with the free $\mathrm{NH}_{2}$-moiety that was present in $\mathbf{5}$ and $\mathbf{6}$. However, this reaction occurred readily in both DCM and toluene, thus these solvents were used. Purification of $\mathbf{5}$ and $\mathbf{6}$ was not needed since the reactions went to completion. These reactions could be followed easily by observing the colour change. Generally the bright red ethoxy tungsten(0) pentacarbonyl heteroaryl carbene (1 and 2) solution would change to a bright yellow colour.

- $\quad$ The formation of complexes $\mathbf{7}$ and $\mathbf{8}$, respectively, was readily accomplished by heating the monocarbene complex 1 or $\mathbf{2}$ with ethylene diamine to allow for substitution of a carbonyl ligand (Scheme 1). The product precipitated out of solution as an orange solid, allowing for effortless purification. Complexes $\mathbf{7}$ and $\mathbf{8}$ were not readily soluble in solvents such as hexane and DCM.

\section{cterization of carbene complexes}

Complexes 1-8 were characterized using ${ }^{1} \mathrm{H},{ }^{13} \mathrm{C}$ NMR and infrared spectroscopy as well as mass spectrometry. Atom-numbering schemes are shown in figures 4-9. Altering the heteroatom substituent on the carbene is expected to have a large effect on all of the spectra recorded for the complexes. Amino groups are known to be better $\pi$-donor substituents on carbenes than ethoxy groups. ${ }^{30,31,32}$ The carbene carbon and the heteroaryl substituent should thus be more shielded in aminocarbenes than in ethoxycarbenes. 
- The ${ }^{1} \mathrm{H}$ NMR spectra of the aminolysis products indicated several interesting changes due to the replacement of the ethoxy group with a cyclohexyl amine moiety. Firstly, and most notably, the order of the proton chemical shifts changed for the thienyl aminocarbene derivatives $(\mathbf{3}, \mathbf{5}, \mathbf{7})$, when compared to the ethoxycarbene complex (1). Protons in the same relative relationship to one another have the same coupling constants. Assignments for $\mathrm{H} 8$ and $\mathrm{H} 10$ could be made by examining the coupling constants. For 1, H8 is found more downfield than H10. The assignments clearly showed an inversion of these proton chemical shifts, relative to one another for 3, 5 and 7, and H10 now has the more downfield shift. The altered relative chemical shifts observed for $\mathrm{H} 8$ and $\mathrm{H} 10$ indicate the large effect aminolysis has on the carbene carbon. This order was also noted for the $\mathrm{Cr}$ analogue by Connor et.al. ${ }^{33}$ For all the furyl carbene complexes $(\mathbf{2}, \mathbf{4}, \mathbf{6}, \mathbf{8}), \mathrm{H} 10$ has the more downfield chemical shift value.

- The protons of the heteroaryl ring will be more shielded and have more upfield shifts for the aminocarbene complexes (3-8) when compared to the corresponding ethoxy derivative (1 or $\mathbf{2}$ ). It is important to note that for both complexes $\mathbf{3}$ and $\mathbf{4}$, two isomers were observed on the NMR spectra, denoted isomer $A$ for the major isomer and isomer $B$ for the minor isomer in each case. However, the concentration difference was much more pronounced for the thienyl derivative $(90: 10)$ than the furyl derivative (65:35). Two isomers were also observed for amino dimanganese thienyl and furyl carbene complexes. ${ }^{34}$ Aminocarbenes are known to exhibit both $E$ and $Z$ configurations (Figure 2). ${ }^{35}$ These isomers occur due to the restricted rotation about the $\mathrm{N}-\mathrm{C}_{\text {carbene }}$ bond, which has double bond character due to $\pi$ donation from the nitrogen atom to the carbene carbon (Figure 2). This is ascribed to better $\pi$-donor ability of the nitrogen lone pair of the amino substituent to stabilise the carbene carbon compared to the ethoxy substituent. $^{36}$

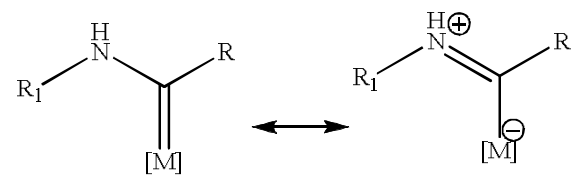

Resonance form 1<smiles>[R]C(=[W])[Tl]N([R1])C([R])=[W]</smiles>

(Z)<smiles>[R1]N([TlH])C(=[W+2])c1[Y]ccc1</smiles><smiles>[R1]N([TlH])C(=[R4]([O-])[O-])c1[Y]ccc1</smiles>

Conformer $1 ;(Z, E)$<smiles>[R1]N([R10])C(=[W])c1[Y]ccc1</smiles><smiles>[R1]N([TlH])C(c1[Y]ccc1)=[W+]([O-])[O-]</smiles>

Figure 2. Resonance forms of $Z$ and $E$ configurations of the aminocarbene substituent

- In addition, the heteroaryl ring may have the heteroatom either facing to or away from the metal center. There are hence four different conformers possible for $\mathbf{3}$ and $\mathbf{4}$ (Figure 3).

$\bullet$

\section{Figure 3. Four possible conformers for complexes 3 and 4}

- It was noted by Streubel ${ }^{37}$ and Moser and Fischer ${ }^{35}$ that the chemical resonance observed for the amino proton of $Z$ aminocarbenes is lower than in $E$ aminocarbenes. The downfield shift observed for the $E$ amino proton is due to deshielding of the proton by the metal center. Comparison of the chemical shifts of N-H and $\mathrm{H} 11$ found for isomers $A$ and $B$ of $\mathbf{3}$ indicates that isomer $A$ has a $Z$ amino configuration, while isomer $B$ should have the $E$ amino configuration. The chemical resonance observed for $\mathrm{H} 8$ of $\mathbf{3}$ is shifted more upfield in isomer $B$ than in isomer $A$, which indicates two different conformations for the heteroaryl ring. $\mathrm{H} 8$ would be shifted most downfield when closest to the metal center (E-conformation). This leads to the conclusion that isomer $A$ of $\mathbf{3}$ has a conformation similar to conformer 1 (i.e. $Z, E$ ) in Figure 3, while isomer $B$ of $\mathbf{3}$ is proposed to have the same conformation as conformer 4 . The crystal structure found for 3 is also the major isomer in solution, i.e. conformer 1. Similar reasoning did not hold for the furyl derivative, 4. The preferred conformation could not be deduced from the ${ }^{1} \mathrm{H}$ NMR data. However, it is clear that different conformations are preferred for complex 3 than complex 4 . However, since only a single isomer, corresponding to conformer 1 (Figure 3) was observed in the crystal structures of both derivatives (3 and 4), it is suggested that this phenomenon occurs mainly in solution. When compared with cyclohexyl amino chromium carbene complexes synthesised by Connor et.al., ${ }^{33}$ a similar trend in the proton chemical shifts is observed. The shifts are, however, more upfield in the complex synthesised by Connor et.al. on both the ${ }^{1} \mathrm{H}$ and ${ }^{13} \mathrm{C}$ spectra. The difference is most likely due to different $\mathrm{Y}$ groups present on the carbene, as well as the different metals, Cr vs. W.

- The most notable change on the ${ }^{13} \mathrm{C}$ NMR spectra of the aminocarbene complexes compared to the ethoxycarbene analogues, is the large upfield shift (50-60 ppm) for the carbene carbon (C6) resonance. Similar decreases were noted in literature when ethoxy substituents were replaced with amines. ${ }^{33,25}$ Increased $\pi$-donation from the amino group when compared to the ethoxy group, decreases $\pi$-contribution needed from the heteroaryl ring, resulting in the upfield shift of the carbene carbon resonance. The carbene chemical shifts ranged from $218 \mathrm{ppm}$ to $246 \mathrm{ppm}$. These shifts are lower than those observed in literature. ${ }^{38}$ It is interesting to note that the change from an ethoxycarbene to an aminocarbene is not reflected in the ${ }^{13} \mathrm{C}$ carbonyl shifts of the complexes in this study. However, other aromatic tungsten carbenes also do not show a significant difference in the carbonyl shifts when the ethoxy group is substituted for an amino substituent. ${ }^{10}$ It has been suggested by Connor et.al. that the larger orbitals found on tungsten do not distribute modifications of the ligand sphere 
to the carbonyl groups as efficiently as in the chromium analogues.

- NMR data confirmed the proposed structures for the ethylene diamine carbene complexes 5-8, which correlated well with literature data. ${ }^{29} \mathbf{7}$ and $\mathbf{8}$ both show a large downfield shift for the two protons on N2. This indicates deshielding of the protons due to coordination of N2 to the metal, as would be expected. Furthermore, the chemical resonances noted for the ${ }^{13} \mathrm{C}$ NMR data of the heteroaryl ring components of complexes 7 and $\mathbf{8}$ were shifted downfield when compared to $\mathbf{5}$ and $\mathbf{6}$. This could indicate increased electron donation from the heteroaryl carbene substituent to the carbene center, however it is more likely that the changes were due to solvent shifts. If the ${ }^{13} \mathrm{C}$ NMR spectra of 5 and 7 are compared, one can clearly observe the changes that occur in the molecule when chelation occurs. Firstly, three carbonyl peaks are observed for complexes $\mathbf{7}$ and $\mathbf{8}$, as one would expect for three non-equivalent carbonyl groups. The carbon resonance peaks associated with the carbonyl groups are further downfield for 7 than for 5. The chemical shifts associated with carbonyl groups depend on the ligand trans to it and follow the following trend: $\mathrm{CO}<$ amine $<$ carbene. The spectra of $\mathbf{7}$ and $\mathbf{8}$ clearly indicate that this trend was followed since the resonance peak associated with $\mathrm{CO} 3$, which is trans to the amine, is only $3 \mathrm{ppm}$ upfield from that of $\mathrm{CO} 1$, which is trans to the carbene. Lastly, the ${ }^{13} \mathrm{C}$ resonance peak for the carbene carbon, C6, is shifted downfield when 7 is compared with $\mathbf{5}$, indicating that the carbene is more deshielded in $\mathbf{7}$ than in $\mathbf{5}$.

\section{IR Spectroscopy}

- Metal pentacarbonyl systems are expected to have $\mathrm{C}_{4 \mathrm{v}}$ symmetry with three IR-active bands. ${ }^{39}$ However, the presence of a bulky L ligand such as a carbene can result in a fourth band being seen. Complexes $\mathbf{1}$ and $\mathbf{2}$ do not reflect this due to extensive overlap of the various bands. Only the $A_{l}^{2}$ band could be assigned unambiguously. The second band represents overlap of the other three expected bands. On the spectra of 3 and 4 only one set of bands was observed for both isomers. Metal tetracarbonyl systems $\left(\mathrm{M}(\mathrm{CO})_{4} \mathrm{~L}_{1} \mathrm{~L}_{2}\right)$ show varying symmetry patterns which depend both on the substitution pattern and the nature of the ligand L. On the two metal tetracarbonyl complexes $\mathbf{7}$ and $\mathbf{8}$, four strong bands were observed.

- $\quad$ The $A_{1}^{2}$ band in metal pentacarbonyl systems is seen as the distinctive CO frequency. ${ }^{40}$ If this frequency is considered as distinctive for all the carbonyl systems studied, then a correlation between the compounds can be made. There is a marked decrease in the wavenumber of the $A_{1}$ band with each successive carbonyl substitution, which correlates well with increased electron density being available for metal $\pi$-backbonding to the carbonyl groups upon substitution for a weaker $\pi$-acceptor ligand. In conclusion, it can thus be seen that each set of complexes has a distinctive IR pattern which can be used for identification, and reflects the changes in metal $\pi$ donation.

\section{Crystallography}

- Suitable crystals of 1-4, 6 and 8 were obtained from dichloromethane:hexane $(1: 1)$ solutions and molecular structures determined with single-crystal X-ray diffraction analysis. The molecular structures of these com- plexes with the atom-numbering scheme are shown in figures 4-9. Selected bond lengths, bond and dihedral angles are given in Table 1. Only the major orientation of the thienyl substituent in $\mathbf{3}$ is shown in Figure 6, as this structure has some disorder in the thienyl ring. The ring adopts two orientations and the occupancy of the positions of $\mathrm{C} 8$ and $\mathrm{S} 1$ was refined to a ratio of 56.4:43.6 for $\mathrm{S} 1: \mathrm{C} 8$. The complexes $\mathbf{1 - 4}, \mathbf{6}$ and $\mathbf{8}$ crystallized in the following space groups: $P 2{ }_{1} / m, A m a 2$, $P 2_{1} / m, P-1, P 2_{1} / n, C 2 / c$, respectively.

$\bullet$

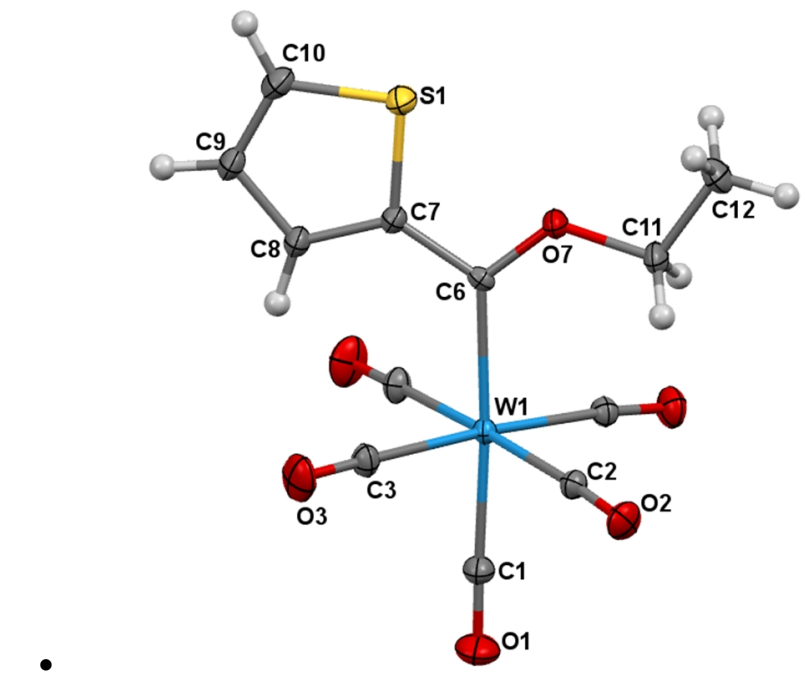

Figure 4. Perspective view of 1 with thermal ellipsoids drawn at the $50 \%$ probability level

- These octahedral complexes all have a planar conformation with the heteroaromatic ring, the carbene carbon atom (C6), the carbonyl group trans to the carbene bond $(\mathrm{CO} 1)$, the metal $(\mathrm{W})$ and the heteroatom $(\mathrm{O} 7 / \mathrm{N} 1)$ all in the same plane. Of importance to note is the anti conformation (dihedral angle $180^{\circ}$ ) of the heteroatom $(\mathrm{S} / \mathrm{O})$ in the heteroaromatic ring with respect to the $07 / \mathrm{N} 1$ group in 2 . Both syn and anti conformation are exhibited by 3 in a ratio of 56.4:43.6. The other complexes all have syn orientations for these substituents.

- The $\mathrm{W}-\mathrm{C}_{\text {carbonyl }}$ bond distances vary significantly. The $\mathrm{W}-\mathrm{C} 1$ bonds that are trans to the $\mathrm{W}-\mathrm{C}_{\text {carbene }}$ bonds have similar distances, varying from $1.994 \AA$ to $2.019 \AA$. This is shorter than the average $\mathrm{W}-\mathrm{C} c i$ s bond distances that vary from $2.037 \AA$ to $2.100 \AA$, as expected. The carbene is a weaker $\pi$-acceptor ligand than the carbonyl group and thus allows for stronger $\pi$-donation from the metal to the trans carbonyl groups.

- The $\mathrm{W}-\mathrm{C}_{\text {carbene }}$ bond distances are influenced by the nature of the non-aromatic heteroatom substituent on the $\mathrm{C}_{\text {carbene. }}$ In $\mathbf{1}$ and $\mathbf{2}$, both with OEt substituents, the average bond distance for W-C6 is $2.204 \AA$, shorter than the average value of $2.235 \AA$ observed for $\mathbf{6}$ and $\mathbf{8}$ with NCCN substituents. The largest average bond distance is observed for W-C6 in $\mathbf{3}$ and $\mathbf{4}$ with CHA groups is $2.260 \AA$. This is consistent with resonance form II in Figure 2. The planar geometry around the $\mathrm{C}_{\text {carbene }}$ reflects the $\mathrm{sp}^{2}$ character of this atom. The C7-C6-O6 bond angles in $\mathbf{1}$ and $\mathbf{2}$ are smaller than the C7-C6-N1 angles in 3, 4, 6 and 8 . The reported $\mathrm{W}=\mathrm{C}$ values are consistent with literature values for similar complexes. ${ }^{24,41}$ 


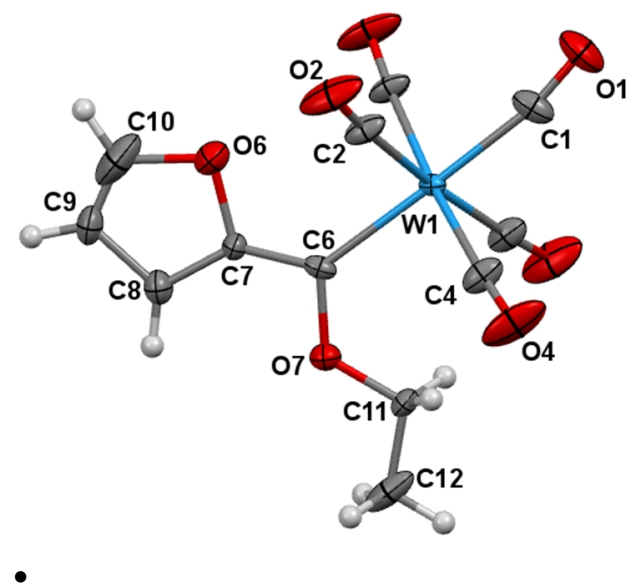

Figure 5. Perspective view of 2 with thermal ellipsoids drawn at the $50 \%$ probability level

- In complex 2, the C6-C7 bond of 1.344(10) $\AA$ is significantly shorter, while the C6-O7 bond is meaningfully longer than in the other complexes. This may be a result of stabilization of the anti conformation due to some orbital interaction between the lone pairs of O6 and antibonding orbitals on the two carbonyls $\mathrm{CO} 2{ }^{42}$

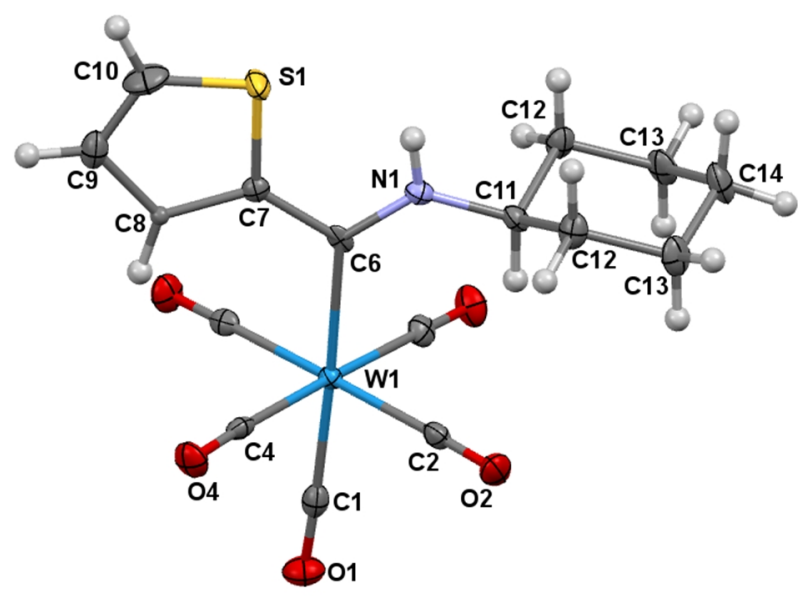

Figure 6. Perspective view of 3 with thermal ellipsoids drawn at the $50 \%$ probability level

Table 1. Selected Bond Lengths (§̊), Bond and Dihedral Angles (deg)

$\begin{array}{lllllll} & \mathbf{1} & \mathbf{2} & \mathbf{3} & \mathbf{4} & \mathbf{6} & \mathbf{8} \\ \text { W1-C6 } & 2.208(2) & 2.199(3) & 2.269(5) & 2.251(4) & 2.240(1) & 2.231(5) \\ \text { W1-CO1 } & 2.019(3) & 2.009(4) & 2.006(5) & 2.000(4) & 2.010(2) & 1.994(6) \\ \text { W1-COcis }{ }^{\mathrm{a}} & 2.049(2) & 2.043(7) & 2.048(4) & 2.040(4) & 2.037(2) & 2.100(6) \\ & & & & & & 1.939(5)(\mathrm{CO} 3) \\ \text { C6-C7 } & 1.441(3) & 1.344(10) & 1.473(6) & 1.466(5) & 1.453(3) & 1.451(7) \\ \text { C7-C8 } & 1.384(3) & 1.356(8) & 1.411(12) & 1.350(5) & 1.373(3) & 1.347(7) \\ \text { C8-C9 } & 1.409(4) & 1.420(7) & 1.451(12) & 1.424(5) & 1.428(3) & 1.416(8) \\ \text { C9-C10 } & 1.365(4) & 1.135(22) & 1.335(8) & 1.336(6) & 1.337(4) & 1.339(8) \\ \text { C10-S1/O6 } & 1.705(3) & 1.448(19) & 1.590(7) & 1.362(4) & 1.369(3) & 1.352(6) \\ \text { C7-S1/O6 } & 1.742(2) & 1.423(9) & 1.701(6) & 1.392(4) & 1.381(3) & 1.389(6)\end{array}$




$\begin{array}{lllllll}\text { C6-N1/O7 } & 1.330(3) & 1.414(10) & 1.330(5) & 1.320(5) & 1.313(3) & 1.317(6) \\ \text { C1-W1-C6 } & 176.4(9) & 178.6(6) & 177.43(18) & 177.81(14) & 178.82(8) & 173.82(17) \\ \text { W1-C6-O7/N1 } & 128.58(15) & 124.3(6) & 125.5(3) & 127.3(3) & 126.29(14) & 123.7(4) \\ \text { W1-C6-C7 } & 124.84(15) & 129.8(6) & 122.3(3) & 120.8(3) & 122.51(13) & 122.5(3) \\ \text { O7/N1-C6-C7 } & 106.57(18) & 105.8(3) & 112.2(4) & 111.9(3) & 111.19(17) & 113.7(4) \\ \text { O7/N1-C6-C7-S1/06 } & 0.000(1) & 180.000(1) & 0.000(2), & 6.1(4) & 0.2(3) & 7.4(7) \\ \text { W1-C6-O7/N1-C11 } & 0.000(1) & 0.000(1) & 0.000(1) & -4.9(5) & 4.7(3) & -5.3(7) \\ \text { W1-C6-C7-S1/O6 } & 180.000(1) & 0.000(1) & 180.000(1), & -172.2(2) & 178.97(14) & -169.0(3)\end{array}$

${ }^{\text {a }}$ Average cis carbonyl bond length

${ }^{\mathrm{b}}$ Two values due to disordered thienyl ring

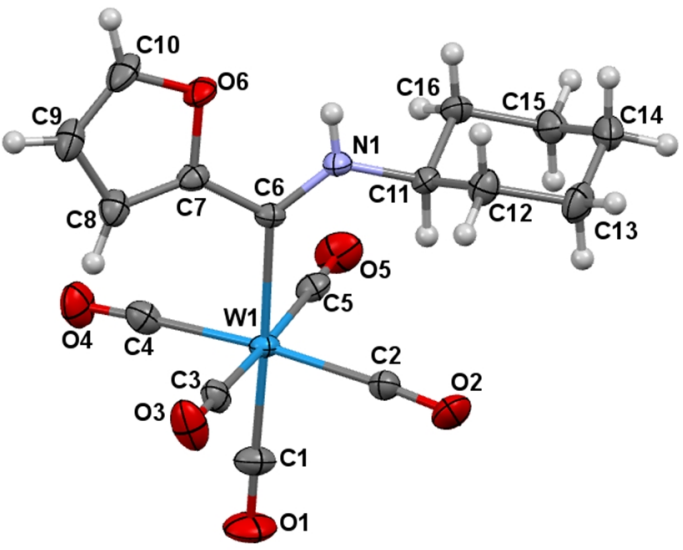

Figure 7. Perspective view of $\mathbf{4}$ with thermal ellipsoids drawn at the $50 \%$ probability level

- If one considers the various $\mathrm{C}-\mathrm{N}$ bonds, it can be clearly seen that the $\mathrm{C}_{\text {carbene }} \mathrm{N} 1$ bonds are much shorter than the $\mathrm{C}-\mathrm{N} 2$ bond of the chelate backbone in complex $\mathbf{8}$. The reduced $\mathrm{C}-\mathrm{N} 1$ bond length for the $\mathrm{C}_{\text {carbene- }}-\mathrm{N} 1$ bond shows increased bond order between this carbon and nitrogen (Resonance form II, Figure 2). The only exception to this trend is $\mathbf{3}$. This may be ascribed to the orientational disorder of the heteroarene substituent in the structure.

- 8 has a six-membered chelate ring formed by the metal, carbene carbon and the ethylene diamine chelate. Sixmembered rings generally take on a chair conformation; however, when a double bond is present this is not possible.

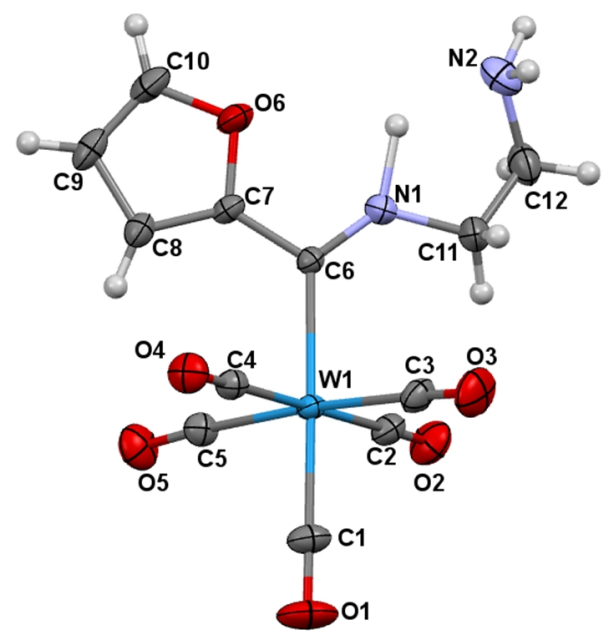

Figure 8. Perspective view of 6 with thermal ellipsoids drawn at the $50 \%$ probability level

- The ring will then take on the chair conformation as far as possible resulting in puckering. Puckering of this nature was observed in $\mathbf{8}$ for the N2-C12-C11-N1-C6 portion of the structure. The $\mathrm{W}-\mathrm{CO} 3$ bond is much shorter than the bond length of either of the other carbonyl groups in $\mathbf{8}$, as well as the carbonyl bonds in the other structures (Table 1). Amines, $\sigma$-donor ligands, do not have $\pi$-interactions with the metal. Therefore the carbonyl group trans to the amine will have the largest amount of $\pi$-metal donation and the shortest bond length, as observed. 


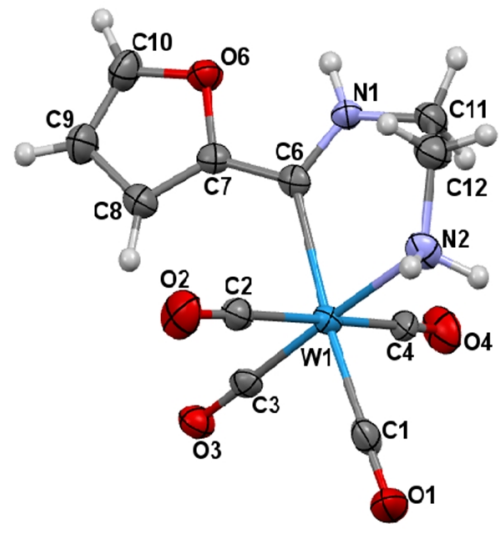

Figure 9. Perspective view of 8 with thermal ellipsoids drawn at the $50 \%$ probability level

\section{ELECTROCHEMISTRY}

- $\quad$ 1-8 were submitted to an electrochemical study utilizing cyclic voltammetry $(\mathrm{CV})$ and Osteryoung square-wave voltammetry (SW), in order to verify their stability under redox conditions, as well as the chemical and electrochemical reversibility: The CV's at $100 \mathrm{mV} \mathrm{s}^{-1}$ are shown in Figure 10 and the data are summarized in Table 2. All CVs showed one oxidation and one reduction process, indicated with (a) and (b) in Figure 10, respectively.

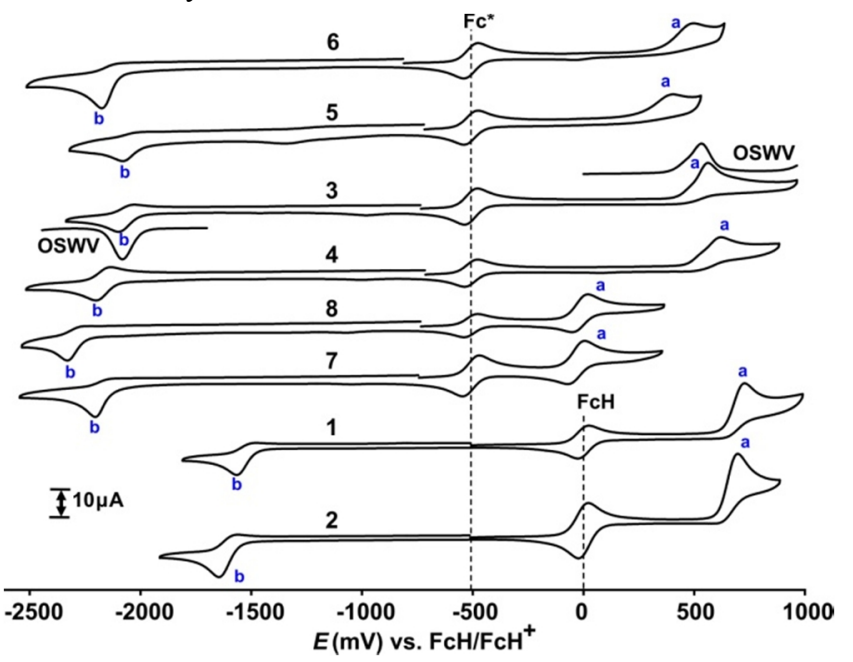

Figure 10. Cyclic voltammograms of c.a. $0.5 \mathrm{mmol} \mathrm{dm}^{-3}$ solutions of 1-8 in $\mathrm{CH}_{3} \mathrm{CN} / 0.1 \mathrm{~mol} \mathrm{dm}^{-3}\left[{ }^{\mathrm{n}}\left(\mathrm{Bu}_{4}\right) \mathrm{N}\right]\left[\mathrm{PF}_{6}\right]$ on a glassy carbon-working electrode at a scan rate of $100 \mathrm{mV} \mathrm{s}$. Osteryoung square wave voltammogram (OSWV) of 3 are also shown. $\mathrm{CV}$ peaks due to the internal standard used, are marked $\mathrm{FcH}$ or $\mathrm{Fc}^{*}$. Scans initiated in the positive direction from $-500 \mathrm{mV}$ (complexes 1 and 2) or from c.a. $-750 \mathrm{mV}$. Oxidation peaks are marked with (a) and reduction peaks with (b).

- The oxidation process is assigned to the oxidation of the tungsten metal on grounds of DFT calculations of fron- tier molecular orbitals (FMOs) of the studied molecules, focusing on the electron delocalization (see the DFT section below). This assignment is in agreement with the experimental assignment of the oxidation of a series of five alkoxy, amino and hydrazino carbene complexes of tungsten by Licandro et. al..$^{43}$ and two aminocarbene complexes of tungsten reported by Ludvík. ${ }^{44}$ The reduction peak observed at potentials below $1500 \mathrm{mV}$ vs. $\mathrm{Fc} / \mathrm{Fc}^{+}$is localized on the carbene moiety according to Ludvík. This assignment is supported by the DFT calculations of 1-8 in this study.

\section{Oxidation}

- $\quad$ The first oxidation peak for complexes 1-8 is observed at $5-20 \mathrm{mV} v s . \mathrm{Fc} / \mathrm{Fc}^{+}$for the tetracarbonyl complexes 7 and 8 , and between 420 and $730 \mathrm{mV} v s . \mathrm{Fc} / \mathrm{Fc}^{+}$for the pentacarbonyl complexes 1-6 of this study. The tungsten carbene complexes 1-6 feature a chemically irreversible first oxidation peak; in other words, the product of the first oxidation step appears not to be chemically stable. For complexes $\mathbf{7}$ and $\mathbf{8}$, however, the oxidation process is electrochemically $(\Delta E=86 \mathrm{mV})$ and chemically $\left(i_{\mathrm{pc}} / i_{\mathrm{pa}}=0.7\right)$ quasi reversible. Electrochemical and chemical reversible redox processes are characterized by $\Delta E=E_{\mathrm{pa}}-E_{\mathrm{pc}}=59 \mathrm{mV}$ and $i_{\mathrm{pc}} / i_{\mathrm{pa}}=1$ (when the diffusion coefficients of the oxidized and reduced forms of the couple are identical or near identical). ${ }^{45}$ Comparing the characteristics of the oxidation peak of complexes 18 it is evident that:

- Thienyl vs. furyl ligand (compare 1 to 2,3 to 4,5 to 6 and 7 to 8): For the aminocarbene complexes $3-8$ the oxidation peak shift between 15 and $95 \mathrm{mV}$ more positive by changing the thienyl ligand ( $\mathrm{Y}$ in Figure 1) to furyl. The shift is positive, as expected due to the higher donor ability of sulfur. For the alkoxy complexes $\mathbf{1}\left(E_{p a}\right.$ $=728 \mathrm{mV})$ and $2\left(E_{\mathrm{pa}}=697 \mathrm{mV}\right)$, the shift is reverse. The same "reverse" trend is obtained for the oxidation potential of the related $\mathrm{Cr}$-alkoxycarbene complexes $\left[\mathrm{Cr}(\mathrm{CO})_{5}\{\mathrm{C}(\mathrm{OEt}) \mathrm{Ar}\}\right], \mathrm{Ar}=$ thienyl $\left(E^{0^{\prime}}=496 \mathrm{mV}\right)$ or furyl $\left(E^{0^{\prime}}=454 \mathrm{mV}\right)^{46,47}$ and for the $\mathrm{Ti}^{\mathrm{IV} / \mathrm{III}}$ couple of $\beta$ diketonato-titanocene complexes $\left[\mathrm{Cp}_{2} \mathrm{Ti}\left(\mathrm{CF}_{3} \mathrm{COCHCOR}\right)\right]^{+}$with $\mathrm{Cp}=$ cyclopentadienyl and $\mathrm{R}=$ thienyl $\left(E^{0^{\prime}}=-619 \mathrm{mV}\right)$ or furyl $\left(E^{0^{\prime}}=-625\right.$ $\mathrm{mV}){ }^{48}$ On the other hand, the oxidation potential for Cr-aminocarbene complexes $\left[\mathrm{Cr}(\mathrm{CO})_{5}\left\{\mathrm{C}\left(\mathrm{NH}_{2}\right) \mathrm{Ar}\right\}\right], \mathrm{Ar}$ $=$ thienyl or furyl were the same, ${ }^{47}$ while for $\mathrm{Cr}$ aminocarbene complexes $\left[\mathrm{Cr}(\mathrm{CO})_{5}\left\{\mathrm{C}\left(\mathrm{N}_{(}\left(\mathrm{CH}_{3}\right)_{2}\right) \mathrm{Ar}\right\}\right]$, the oxidation potential of the complex with $\mathrm{Ar}=$ thienyl $<\mathrm{Ar}=$ furyl. ${ }^{19}$ These results show that the electronegativity of $\mathrm{O}$ and $\mathrm{S}$ alone, cannot forecast the order of oxidation thienyl or furyl-containing complexes.

- Alkoxy- vs. aminocarbene (compare $\mathbf{1}$ and $\mathbf{2}$ to $\mathbf{3}$ and $\mathbf{4}$ or 5 and 6): The alkoxycarbenes are more difficult to oxidize (higher, more positive $E_{\mathrm{pa}}$ ) than the aminocarbenes. This is consistent with the higher electronegativity of the oxygen atom with respect to nitrogen.

- $\quad$ Chelate $v s$. non-chelate (compare 5 and $\mathbf{6}$ to $\mathbf{7}$ and $\mathbf{8}$ ): the chelates (7 and 8) are oxidized $400-450 \mathrm{mV}$ less positively (much more easily) than the corresponding non-chelates (5 and 6). This is expected since $\mathrm{CO}$ is a better $\pi$-acceptor than an amine ligand. With five $\mathrm{CO}$ groups having strong $\pi$-acceptor properties, electron density on $\mathrm{W}$ is diminished and oxidation is thus more 
difficult. In the chelate, one electron withdrawing carbonyl is replaced by a nitrogen-containing ligand, an electron-donating group; therefore, the oxidation of the chelate is significantly easier. This result is in agreement with the ease of oxidation of the non-chelated pentacarbonyl[(N,N-dimethylamino)phenylmethylene $]-$ tungsten(0) complex (300-400 $\mathrm{mV}$ less positively) vs. the chelated tetracarbonyl $\left[\left(\eta^{2}-\mathrm{N}-\right.\right.$ allyl-Nallylamino)phenylmethylene]-tungsten(0) complex. ${ }^{44}$

- Electron donation by the nitrogen atom of the chelate ring in complexes $\mathbf{7}$ and $\mathbf{8}$ stabilize the oxidized W(I) radical long enough on the timescale of the $\mathrm{CV}$ experiment that the oxidation process is electrochemically and chemically quasi reversible, contrary to the oxidation of the other W-carbenes of this study, complexes 1-6, that are electrochemically and chemically irreversible.

- Experimentally, in solution on NMR, two isomers each of 3 and $\mathbf{4}$ were observed. The $\mathrm{W}(0)$ oxidation peak of the $\mathrm{CV}$ of both $\mathbf{3}$ and $\mathbf{4}$ in Figure 10 showed a small shoulder at the lower potential side, that can be interpreted as the presence of two $\mathrm{W}(0)$ isomers in solution, being oxidized at a slightly different oxidation potential. The Osteryoung square wave voltammogram (OSWV) of 3 in Figure 10 shows a very poorly resolved shoulder for the oxidation process. The reduction process of $\mathbf{3}$ at $2028 \mathrm{mV} \mathrm{s}^{-1}$ did not show any trace of a second isomer being reduced at a slightly different reduction potential.

The largest shift in the oxidation potential for complexes 1-8 is observed for the chelates ( $\mathbf{7}$ and $\mathbf{8}$ ) relative to complexes 1-6. This is understandable since the oxidation center is mainly $\mathrm{W}$-metal based. The electronic influence of any group or ligand directly attached to $\mathrm{W}$ will be more pronounced than the influence of substituents on the carbene ligand.

\section{Reduction}

- $\quad$ The first reduction peak for complexes 1-8 is observed at -1565 to $-1545 \mathrm{mV} v s$. $\mathrm{Fc} / \mathrm{Fc}^{+}$for the alkoxycarbene complexes $\mathbf{1}$ and 2, and between -2330 and $-2070 \mathrm{mV}$ $v s . \mathrm{Fc} / \mathrm{Fc}^{+}$for the aminocarbene complexes 3- 8 of this study. For complexes $\mathbf{1}$ and $\mathbf{2}$ a small re-oxidation peak is observed with $\Delta E=86 \mathrm{mV}$ and $i_{\mathrm{pa}}<<i_{\mathrm{pc}}$ making the reduction of these complexes chemically irreversible, but electrochemically quasi reversible. For complexes 3 and 4 the re-oxidation peak intensifies with increasing scan rate (Figure 11 for 4 ) and $\Delta E=66-70 \mathrm{mV}$ and making the reduction of these complexes 3 and 4 chemically quasi reversible, and electrochemically reversible. An increase in the $i_{\mathrm{pa}} / i_{\mathrm{pc}}$ ratio with increase in scan rate indicates that the reduced $\mathrm{W}$-carbene radical complexes $\mathbf{3}$ and $\mathbf{4}$ are stabilized long enough on the time scale of the $\mathrm{CV}$ to be re-oxidized. Comparing the characteristics of the reduction peak of complexes 1-8 it is evident that:

- Thienyl vs. furyl ligand (compare 1 to 2,3 to 4,5 to 6 and 7 to 8): The reduction peak shifts c.a. $100 \mathrm{mV}$ more negative by changing the thienyl ligand ( $\mathrm{Y}$ in Figure 1) to furyl. The thienyl-containing carbenes are thus reduced at a less negative potential. The reduction potential for $\left[\mathrm{Cr}(\mathrm{CO})_{5}\{\mathrm{C}(\mathrm{OEt}) \mathrm{Ar}\}\right], \mathrm{Ar}=$ thienyl $\left(E^{0^{\prime}}=-1552\right.$ $\mathrm{mV})$ or furyl $\left(E^{0^{\prime}}=-1649 \mathrm{mV}\right)$ is in the same order. ${ }^{46}$ The opposite order is observed for the reduction of $\left[\mathrm{Cr}(\mathrm{CO})_{5}\left\{\mathrm{C}\left(\mathrm{N}\left(\mathrm{CH}_{3}\right)_{2}\right) \mathrm{Ar}\right\}\right]$, the reduction potential of the complex with $\mathrm{Ar}=$ thienyl $<\mathrm{Ar}=$ furyl $^{19}$
- Alkoxy- vs. aminocarbene (compare $\mathbf{1}$ and $\mathbf{2}$ to $\mathbf{3}$ and $\mathbf{4}$ or 5 and 6): The reduction potential shifts with more than $500 \mathrm{mV}$ more positive when changing from an amino to an ethoxy group, as the carbene carbon atom becomes more positively charged when bonded to the more electronegative oxygen atom, compared to nitrogen. The alkoxycarbenes are thus reduced more easily than the aminocarbenes, at a less negative potential.

- $\quad$ Chelate vs. non-chelate (compare 5 and 6 to 7 and 8): The chelates ( 7 and 8 ) are reduced $120-160 \mathrm{mV}$ more negative than the corresponding non-chelates (5 and $\mathbf{6})$. The shift in the reduction potential of the chelate $v s$ non-chelate is not as significant as the shift observed for the oxidation potential $(400-450 \mathrm{mV})$.

The largest shift in the reduction potential for complexes $\mathbf{1 - 8}$ is observed for the ethoxycarbenes ( $\mathbf{1}$ and $\mathbf{2}$ ) relative to the aminocarbenes 3-8. Since the reduction center is distributed over the carbene carbon, the nitrogen or oxygen heteroatom and the furyl or thienyl substituent, the electronic properties of heteroatom will directly influence the reduction potential.

- The attempts at interpretation of experimental cyclic voltammetry data should, however, be supported by quantum chemical calculations.

Table 2: Cyclic voltammetry data of $0.5 \mathrm{mmol} \mathrm{dm}^{-3}$ solutions of 1-8 in $\mathrm{CH}_{3} \mathrm{CN}$ containing $0.1 \mathrm{~mol} \mathrm{dm}^{-3}$ $\left[\mathrm{N}\left({ }^{n} \mathrm{Bu}\right)_{4}\right]\left[\mathrm{PF}_{6}\right]$ as supporting electrolyte at a scan rate of $100 \mathrm{mV} \mathrm{s}^{-1}$ and $20^{\circ} \mathrm{C}$. Potentials are reported in $\mathrm{mV}$ relative to the $\mathrm{FcH} / \mathrm{FcH}^{+}$couple.

\begin{tabular}{lllllllll}
\hline \multicolumn{3}{c}{ Oxidation } & \multicolumn{5}{c}{ Reduction } \\
& $E_{\mathrm{pa}}$ & $E_{\mathrm{pc}}$ & $\begin{array}{l}\Delta E \\
(\mathrm{mV})\end{array}$ & $\begin{array}{l}E^{0 /} \\
(\mathrm{mV})\end{array}$ & $E_{\mathrm{pa}}$ & $E_{\mathrm{pc}}$ & $\begin{array}{l}\Delta E \\
(\mathrm{mV})\end{array}$ & $\begin{array}{l}E^{0 /} \\
(\mathrm{mV})\end{array}$ \\
\hline 1 & 728 & - & & & -1478 & -1564 & 86 & -1521 \\
2 & 697 & - & & & -1559 & -1645 & 86 & -1602 \\
3 & 562 & - & & & -2028 & -2098 & 70 & -2063 \\
4 & 620 & - & & & -2134 & -2200 & 66 & -2167 \\
5 & 404 & - & & & - & -2080 & & \\
6 & 498 & - & & & - & -2174 & & \\
7 & 5 & -71 & 76 & -33 & - & -2203 & & \\
8 & 20 & -50 & 70 & -15 & - & -2330 & \\
\hline
\end{tabular}

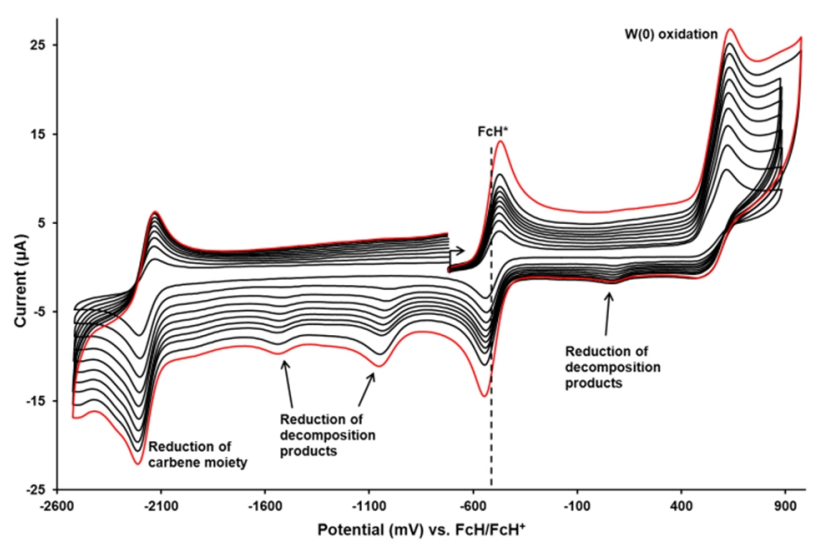


Figure 11. Cyclic voltammograms of c.a. $0.5 \mathrm{mmol} \mathrm{dm}^{-3}$ solutions of 4 in $\mathrm{CH}_{3} \mathrm{CN} / 0.1 \mathrm{~mol} \mathrm{dm}^{-3}\left[{ }^{\mathrm{n}}\left(\mathrm{Bu}_{4}\right) \mathrm{N}\right]\left[\mathrm{PF}_{6}\right]$ on a glassy carbon-working electrode at a scan rate of at scan rates of 50 (smallest currents) till $500 \mathrm{mV} \mathrm{s}^{-1}$ (indicated in red) in $50 \mathrm{mV}$ increments. Decamethylferrocene, $\mathrm{FcH}^{*}$, was used as internal standard. The small reduction peaks are ascribed to decomposition products that are generated during $W(0)$ oxidation since these peaks are absent if the scans are initiated in the negative direction. Scans initiated in the positive direction from $-750 \mathrm{mV}$.

\section{DFT Study}

- Quantum chemical calculations are presented in order to characterize the oxidation and reduction orbitals and to prove and strengthen the interpretation of experimental observations.

- From a molecular point of view, oxidation of a complex involves the removal of an electron from the highest occupied orbital (HOMO) of the complex, leading to a positively charged cation. The character of the HOMO will thus show where the oxidation process will take place. Similarly, the LUMO of the oxidized cation will show where the reduction took place. The localization of the remaining unpaired electron of the oxidized cation can be visualized by a spin-density plot of the oxidized species (charge $\mathrm{q}=+1$, spin $\mathrm{S}=1 / 2$ ). In evaluating the HOMO of the neutral complexes 1-8, the LUMO and the spin density plot of the cations of 1-8 (Figure 12), it is clear that the oxidation center of $\mathbf{1 - 8}$ is localized on the metal center and the carbonyl ligands. The W-metal d-orbital contribution to the HOMO, is in all cases between 62 and $64 \%$, see Table 3. Licandro et. $a l .{ }^{43}$ proposed that for tungsten-carbenes, the first electron oxidation immediately leads to the loss of a second electron, i.e. a two-electron oxidation process. DFT calculations showed that the W(II) singlet state $(\mathrm{S}=0$, charge $=+2$ ) is more stable than the W(II) triplet state $(\mathrm{S}=1$, charge +2$)$ cation with more than $0.2 \mathrm{eV}$. The second electron oxidation thus involves the abstraction remaining unpaired electron of the oxidized cation that is visualized by a spin-density plot in Figure 12 .

- Reduction of a complex involves the addition of an electron to the LUMO of the complex. The character of the LUMO will thus show where the reduction process will take place. Similarly, the HOMO of the reduced species of the complex will show where the reduction took place. The localization of the added unpaired electron of the reduced anion can be visualized by a spindensity plot of the reduced species (charge $\mathrm{q}=-1$, spin $\mathrm{S}=1 / 2$ ). The molecular orbital and spin pictures in Figure 13 show that the center of reduction (LUMO orbital) in 1-8, is distributed over the carbene carbon, the nitrogen or oxygen heteroatom and the furyl or thienyl substituent. This fact demonstrates that the resonance form II of Fischer electrophilic alkoxy- and aminocarbene complexes (Figure 2 top), the form with the formal $\mathrm{C}=\mathrm{N}$ or $\mathrm{C}=\mathrm{O}$ double bond exists and is reduced.

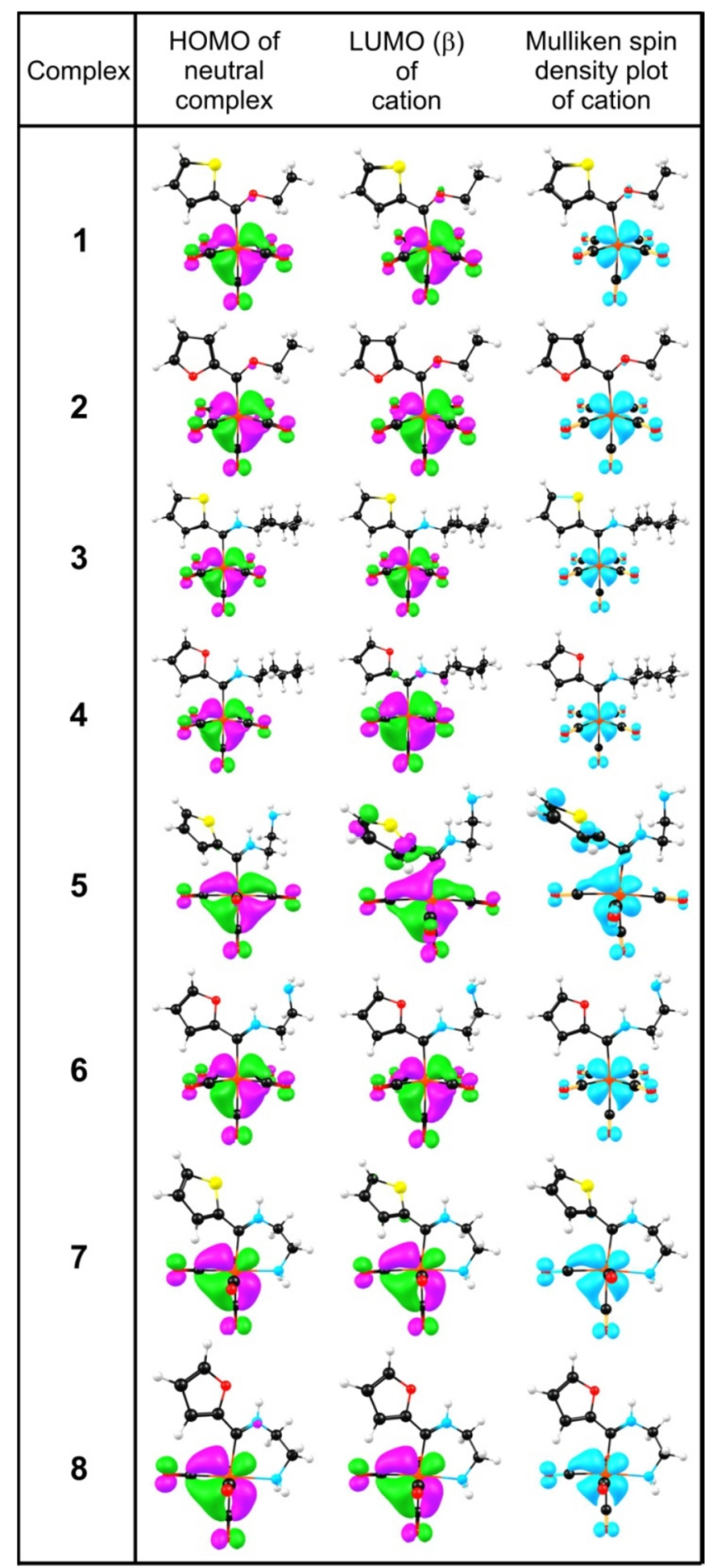

Figure 12. Visualization of (a) the HOMO of the neutral complexes of 1-8, and the (b) LUMO and (c) spin density plots of the oxidized $(q=+1, S=1 / 2)$ complexes $1-8$. The $M O$ and spin density plots use a contour of 0.05 and $0.005 \mathrm{e} / \AA^{3}$, respectively. 


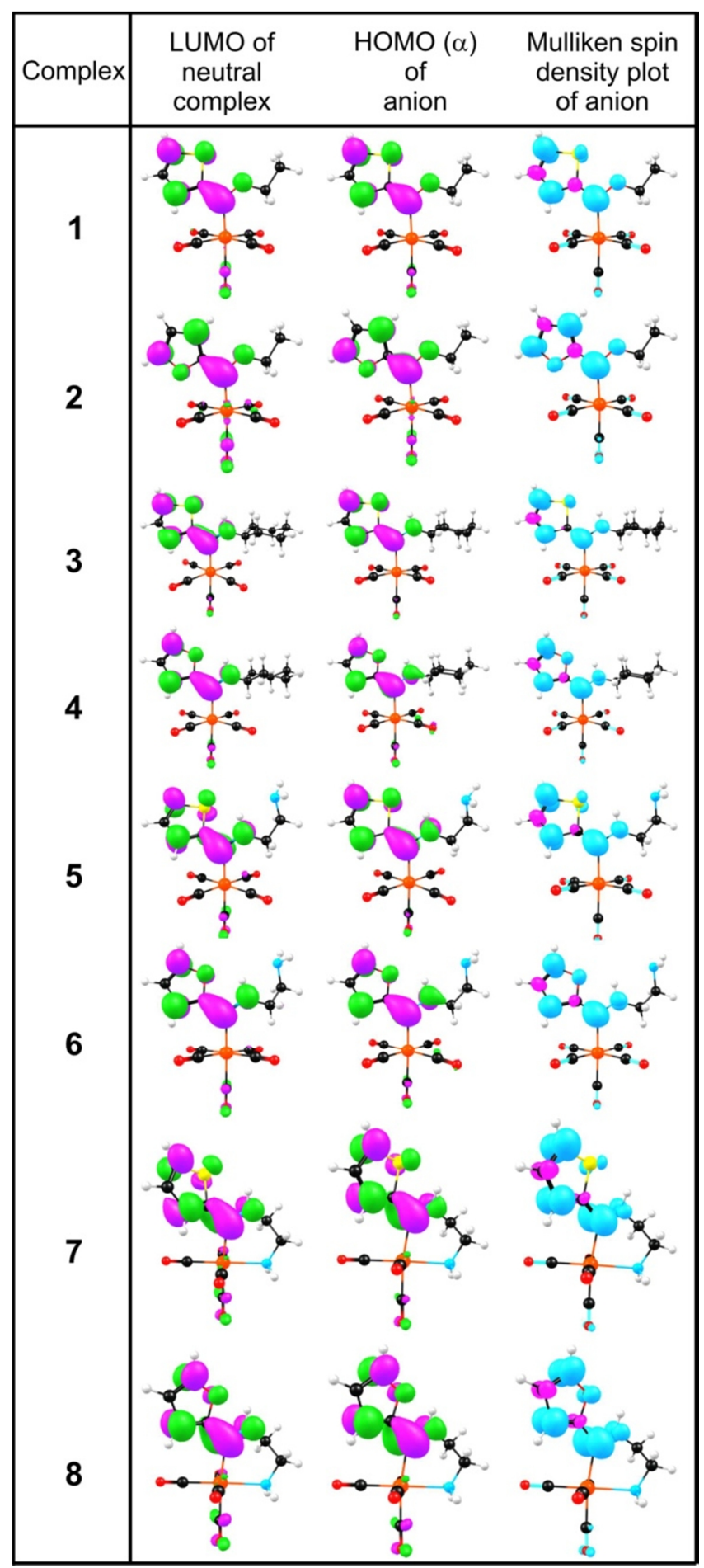

Figure 13. Visualization of (a) the LUMO of the neutral complexes of 1-8 and (b) the HOMO and (c) spin density plot of the reduced radical anion $(q=-1, S=1 / 2)$ of complexes of 1-8. The MO and spin density plots use a contour of 0.05 and 0.005 e $/ \AA^{3}$ respectively.
- Additional support in favor of the HOMO being the oxidation center and the LUMO being the reduction center can be found in the relation of the energy of the HOMO and LUMO to the ease of the oxidation and reduction respectively. In other words, if a relationship exist between the energy of the HOMO, $E_{\mathrm{HOMO}}$, and the experimental peak oxidation potential, $E_{\mathrm{pa}}$, and, similarly, if a relationship exist between the energy of the LUMO, $E_{\mathrm{LUMO}}$, and the experimental peak reduction potential, $E_{\mathrm{pc}}$. This argument is in agreement with the Koopmans' theorem stating that the ionization potential $(I P)$ for a neutral gas-phase compound can be approximated by the negative of HOMO energy $\left(E_{\mathrm{HOMO}}\right)$. Similarly, the LUMO energy $\left(E_{\mathrm{LUMO}}\right)$ provides an approximation of electron affinity $(E A)$. Such correlations have been used successfully to predict redox potentials. ${ }^{49}$

- The linear relationship obtained between the calculated HOMO energy ( $E_{\mathrm{HOMO}}$ in $\mathrm{eV}$ ) of neutral 1-8 and the anodic peak potential $E_{\mathrm{pa}}($ in $\mathrm{mV}$ ), is illustrated in Figure 14(a):

$\bullet$

- $E_{\mathrm{pa}}=-684.99 E_{\mathrm{HOMO}}-3326.38 \quad\left(\mathrm{R}^{2}=\right.$ $0.98)$

$\bullet$

- The calculated electron affinity $I P$ (in $\mathrm{eV}$ ), obtained from the energy difference between the DFT optimized neutral and oxidized species, is related to the anodic peak potential $E_{\mathrm{pa}}$ (in $\mathrm{mV}$ ) by (Figure 15 (a)):

$\bullet$

- $\quad E_{\mathrm{pa}}=735.25 I P-4572.28$ $0.98)$
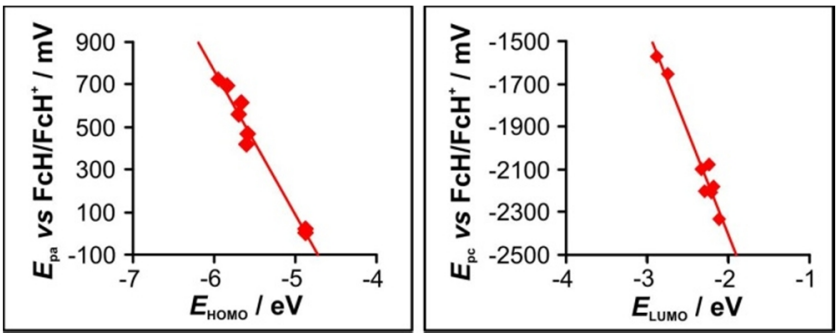

(a)

(b)

Figure 14. Linear relationship between the DFT calculated (a) $E_{\text {HOмо }}$ and the experimental oxidation potential $E_{\mathrm{pa}}$ and (b) $E_{\mathrm{LuMo}}$ and the experimental reduction potential $E_{\mathrm{pc}}$ of complexes 1-8. Data are in Table 2 and Table 3. Experimental potentials are relative to the $\mathrm{FcH} / \mathrm{FcH}^{+}$couple.

- The linear relationship obtained between the calculated LUMO energy ( $E_{\mathrm{LUMO}}$ in $\mathrm{eV}$ ) of neutral 1-8 and the cathodic peak potential $E_{\mathrm{pc}}$ (in $\mathrm{mV}$ ), confirm and quantifies the role of the carbene carbon, the nitrogen or oxygen heteratom and the furyl or thienyl substituent in the reduction process, see Figure 14(b):

$\bullet$

- $E_{\mathrm{pc}}=-965.43 E_{\mathrm{LUMO}}-4311.06 \quad\left(\mathrm{R}^{2}=\right.$ $0.96)$

$\bullet$

Relationships 
- $\quad$ The calculated electron affinity $E A$ (in $\mathrm{eV}$ ), obtained from the energy difference between the DFT optimized neutral and reduced species, is related to the cathodic peak potential $E_{\mathrm{pc}}(\mathrm{in} \mathrm{mV}$ ) by (Figure $15(\mathrm{~b})$ ):

$\bullet$

- $\quad E_{\mathrm{pc}}=1065.37 E A-3226.80$ $0.88)$

$\bullet$

- The equations obtained above for the series 1-8 of Fischer alkoxy- and aminocarbene complexes of tungsten over a large potential range $(>260 \mathrm{mV})$ emphasize the role of the frontier orbitals in the oxidation and reduction process. The relationships obtained, enables prediction of the reduction potential of related complexes by DFT calculations, before synthesizing it. As a result, the oxidation and reduction potential can be modified by the correct combination of heteroatom X, R alkyl or aryl group and Y substituents on the carbene ligand (Scheme 1).

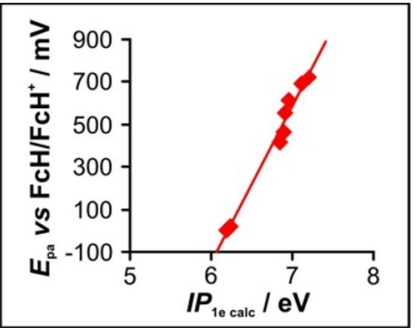

(a)

(b)

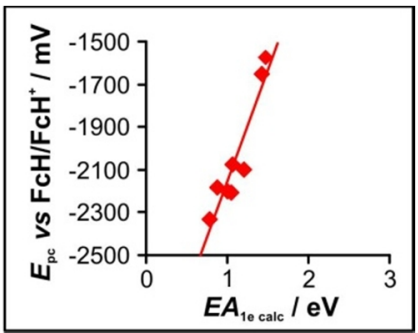

Figure 15. Linear relationship between the DFT calculated (a) ionization potential, $I P$, and the experimental oxidation potential $E_{\mathrm{pa}}$ and (b) electron affinity, $E A$, and the experimental reduction potential $E_{\mathrm{pc}}$ of complexes 1-8. Data are in Table 2 and Table 3 Experimental potentials are relative to the $\mathbf{F c H} / \mathrm{FcH}^{+}$couple.

Table 3: Density functional theory calculated energies and metal d character of the HOMO of complexes 1-8

\begin{tabular}{llllll}
\hline Complex & \multicolumn{2}{l}{ DFT results } \\
& $\begin{array}{l}E_{\mathrm{HOMO}} \\
(\mathrm{eV})\end{array}$ & $\begin{array}{l}E_{\mathrm{LUMO}} \\
(\mathrm{eV})\end{array}$ & $\begin{array}{l}I P \\
(\mathrm{eV})\end{array}$ & $\begin{array}{l}E A \\
(\mathrm{eV})\end{array}$ & $\begin{array}{l}\% \quad \mathrm{~W} d \\
(\mathrm{HOMO})\end{array}$ \\
\hline 1 & -5.94 & -2.87 & 7.23 & 1.48 & 0.64 \\
2 & -5.83 & -2.72 & 7.14 & 1.43 & 0.64 \\
3 & -5.68 & -2.31 & 6.93 & 1.22 & 0.64 \\
4 & -5.65 & -2.28 & 6.98 & 1.01 & 0.64 \\
5 & -5.59 & -2.22 & 6.88 & 1.07 & 0.62 \\
6 & -5.58 & -2.16 & 6.92 & 0.88 & 0.64 \\
7 & -4.86 & -2.19 & 6.21 & 1.05 & 0.63 \\
8 & -4.87 & -2.10 & 6.25 & 0.79 & 0.63 \\
\hline
\end{tabular}

\section{CONCLUSION}

- Aminolysis reactions of Fischer alkoxycarbene complexes $\left[\mathrm{W}(\mathrm{CO})_{5}\{\mathrm{C}(\mathrm{OEt}) \mathrm{Ar}\}\right], \mathrm{Ar}=$ thienyl $(\mathbf{1})$ or furyl (2), with cyclohexyl amine and ethylene diamine at room temperature lead to the substitution of the ethoxy carbene substituent for an amine substituent $(\mathbf{3}, \mathbf{4}, \mathbf{5}$ or 6). When the reaction with ethylene diamine was repeated at elevated temperatures, both aminolysis as well as substitution of a carbonyl ligand ensued, resulting in the formation of a chelate tetracarbonyl tungsten $(0)$ complex (7 or 8). X-ray crystal structures of 1-4, 6 and $\mathbf{8}$ were reported and compared. The electrochemical behaviour of the series of $\left[(\mathrm{CO})_{4} \mathrm{LW}=\mathrm{C}(\mathrm{XR}) \mathrm{Y}\right]$ Fischer complexes of tungsten $(0)$ shows chemically and electrochemically irreversible behaviour. Substitution of one CO ligand with a chelating nitrogen atom on ethylene diamine, leads to the stabilization of the oxidized complex long enough on the timescale of the CV experiment that the oxidation process is electrochemically and chemically quasi reversible. From the electrochemical study it is concluded that different carbene ligand substituents (thienyl $v s$. furyl or alkoxy $v s$. amino) influence the reduction properties of a tungsten $(0)$ carbene complex, while changes in the ligand sphere of the complexes affect the oxidation behavior. This influence of different heteroatoms and ligands on the oxidation and reduction potential is quantified by relationships between the peak oxidation and reduction potential and DFT calculated energies. DFT calculations further showed that the oxidation center is localized on the metal atom (62-64\%) and carbonyl ligands while the reduction center is located on the carbene ligand, distributed over the carbene carbon, the nitrogen or oxygen heteratom and the furyl or thienyl substituent. Application of these results may lead to the design of complexes with a specific electrochemical profile.

\section{EXPERIMENTAL}

All reactions, unless otherwise noted, were performed under inert nitrogen or argon atmospheres using standard Schlenk techniques. ${ }^{50}$ All solvents were freshly distilled, dried and collected under inert conditions, with the exception of toluene. Toluene was not dried, but used after bubbling nitrogen gas through the solvent for 5 to 10 minutes. All other reagents were used directly. Column chromatography was carried out under inert nitrogen and argon atmospheres using silica gel (particle size 0.063$0.200 \mathrm{~mm}$ ) as the stationary phase. All percentage yields were calculated relative to the limiting reactant. All crystallization was done using hexane:DCM diffusion methods. The reagents $\mathrm{W}(\mathrm{CO})_{6}$, butyl lithium $(1.6 \mathrm{M}$ solution in hexane), furan, ethylene diamine and other commercial reagents were used as purchased. NMR spectra were recorded on a Bruker ARX-300, Bruker Ultra Shield 400 Plus AVANCE III, and a Bruker AVANCE 500. NMR spectra were recorded in $\mathrm{CDCl}_{3}, \mathrm{CD}_{2} \mathrm{Cl}_{2}$ or $\mathrm{CD}_{3} \mathrm{CN}$ using deuterated solvent peaks as the internal references. IR spectra were recorded on a Perkin Elmer Spectrum RXI FT-IR spectrophotometer. All spectra were recorded as $\mathrm{KBr}$ pellets and only the vibration bands in the carbonyl stretching region $\left(\mathrm{ca} .1500-2200 \mathrm{~cm}^{-1}\right)$ are reported. Mass spectra were recorded on a SYNAPT G2 HDMS with the TOF-MS method with sampling time of 4 minutes, with direct infusion inlet method. The source was electron spray ionization. Commercial thiophene was purified ${ }^{51}$ and triethyloxonium tetrafluoroborate, ${ }^{52}\left[\mathrm{~W}(\mathrm{CO})_{5}\left\{\mathrm{C}(\mathrm{OEt}) \mathrm{C}_{4} \mathrm{H}_{4} \mathrm{~S}\right\}\right], \mathbf{1},{ }^{53}$ and $\left[\mathrm{W}(\mathrm{CO})_{5}\left\{\mathrm{C}(\mathrm{OEt}) \mathrm{C}_{4} \mathrm{H}_{4} \mathrm{O}\right\}\right], 2,{ }^{54}$ were prepared according to reported literature procedures. Spectroscopic characterization data is included here:

1: Yield: $82.6 \%$, bright orange solid. - ${ }^{1} \mathrm{H}$ NMR $\left(\mathrm{CDCl}_{3}, \mathrm{ppm}\right): 8.14$ (dd, $\mathrm{H} 8,4.1,0.8 \mathrm{~Hz}), \delta 7.80$ (dd, H10, 5.0, 0.6 Hz), 7.20 (dd, H9, 4.8, $4.3 \mathrm{~Hz}$ )

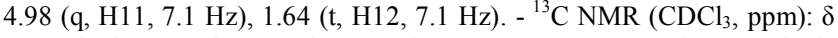
290.7 (C6), 202.5 (s, CO trans $), 197.6\left(\mathrm{t}, \mathrm{CO}_{\text {cis }}, \mathrm{J}_{\mathrm{W}-\mathrm{C}}=126.4 \mathrm{~Hz}\right), 158.3(\mathrm{C} 7)$, 136.5 (C10), 141.5 (C8), 129.0 (C9), 78.6 (C11), 15.0 (C12). - IR (KBr, 
$\left.\mathrm{cm}^{-1}\right): v_{\mathrm{CO}}=2066(\mathrm{~m}), 1916(\mathrm{vs}) .2$ : Yield: $73.3 \%$, bright orange solid. ${ }^{1} \mathrm{H}$ NMR $\left(\mathrm{CDCl}_{3}, \mathrm{ppm}\right): \delta 7.86(\mathrm{dd}, \mathrm{H} 10,1.6,0.7 \mathrm{~Hz}), 7.13(\mathrm{dd}, \mathrm{H} 8,3.7$, $0.7 \mathrm{~Hz}), 6.60$ (dd, H9, 3.7, $1.7 \mathrm{~Hz}), 4.94$ (q, H1 1, $7.1 \mathrm{~Hz}), 1.62$ (t, H12, 7.1 $\mathrm{Hz}) .-{ }^{13} \mathrm{C} \mathrm{NMR}\left(\mathrm{CDCl}_{3}, \mathrm{ppm}\right): \delta 284.8(\mathrm{C} 6), 203.4\left(\mathrm{CO}_{\text {trans }}\right), 197.4\left(\mathrm{CO}_{\text {cis }}\right)$, 166.2 (C7), 150.0 (C10), 113.4 (C8), 113.4 (C9), 78.4 (C11), 15.1 (C12).IR $\left(\mathrm{KBr}, \mathrm{cm}^{-1}\right): v_{\mathrm{CO}}=2067(\mathrm{~m}), 1920(\mathrm{vs})$.

\section{Aminolysis of complexes 1 and 2 with cyclohexyl amine}

- Complex 1 (0.464 g, $1.00 \mathrm{mmol})$ or $2(0.448 \mathrm{~g}, 1.00$ mmol) was dissolved in $20 \mathrm{~mL}$ of THF and $0.245 \mathrm{~g}$ of cyclohexyl amine was added in two portions over a 1 hour period. The solution was allowed to stir for 2 hours, gradually changing colour from dark red to bright yellow. Solvent was removed and a bright yellow crystalline solid with an oily residue was obtained. The product, $\mathbf{3}$ or $\mathbf{4}$, was purified on a silica gel column with hexane:DCM gradient elution.

- 3: Yield: $0.455 \mathrm{~g}, 0.880 \mathrm{mmol}, 88.2 \%$, bright yellow solid. MS $(\mathrm{m} / \mathrm{z}): 433\left([\mathrm{M}]^{+}-3 \mathrm{CO}\right) ; 280\left([\mathrm{M}]^{+}-5 \mathrm{CO}-\right.$ CHA). - ${ }^{1} \mathrm{H}$ NMR $\left(\mathrm{CDCl}_{3}\right.$, ppm): Isomer $A: \delta 8.30$ (s(b), N1-H), 7.50 (dd, H10, 5.1, 1.2 Hz), 7.34 (dd, H8, 3.8, $1.2 \mathrm{~Hz}$ ), 7.12 (dd, H9, 5.1, 3.8 Hz), 4.35-4.52 (m, H11), 1.10-2.20 (m, H12-H14); Isomer $B$ : $\delta 8.64$ (s(b), N1-H), 7.46 (dd, H10, 5.0, 1.1 Hz), 7.07 (dd, H9, 5.0, 3.7 Hz), 6.93 (dd, H8, 3.7, 1.1 Hz), 3.73-3.86 (m, H11), 1.102.20 (m, H12-H14).- ${ }^{13} \mathrm{C} \mathrm{NMR}\left(\mathrm{CDCl}_{3}, \mathrm{ppm}\right)$ : Isomer $A: \delta 235.0\left(\mathrm{t}, \mathrm{C} 6, \mathrm{~J}_{\mathrm{W}-\mathrm{C}}=90.8 \mathrm{~Hz}\right), 202.8\left(\mathrm{t}, \mathrm{CO}_{\text {trans }}, \mathrm{J}_{\mathrm{W}-\mathrm{C}}\right.$ $=127.1 \mathrm{~Hz}), 198.2\left(\mathrm{t}, \mathrm{CO}_{\text {cis }}, \mathrm{J}_{\mathrm{W}-\mathrm{C}}=127.0 \mathrm{~Hz}\right), 157.0$ (C7), 129.5 (C10), 128.1 (C8), 126.9 (C9), 64.9 (C11), 33.0 (C12), 24.9 (C13), 24.4 (C14). Isomer $B: \delta 245.7$ $\left(\mathrm{t}, \mathrm{C} 6, \mathrm{~J}_{\mathrm{W}-\mathrm{C}}=90.8 \mathrm{~Hz}\right), 203.5\left(\mathrm{t}, \mathrm{CO}_{\text {trans }}, \mathrm{J}_{\mathrm{W}-\mathrm{C}}=127.8\right.$ $\mathrm{Hz}), 198.7\left(\mathrm{t}, \mathrm{CO}_{\text {cis }}, \mathrm{J}_{\mathrm{W}-\mathrm{C}}=127.8 \mathrm{~Hz}\right), 150.2(\mathrm{C} 7), 127.8$ (C10), 127.3 (C8), 124.2 (C9), 59.5 (C11), 33.3 (C12), 24.7 (C13), 24.2 (C14).- IR (KBr, cm $\left.{ }^{-1}\right): v_{\mathrm{CO}}=2061$ (m), 1972 (vw), 1950 (s), 1906 (vs). Anal. Calcd for $\mathrm{C}_{16} \mathrm{H}_{15} \mathrm{NO}_{5} \mathrm{SW}: \mathrm{C}, 37.16 ; \mathrm{H}, 2.92 ; \mathrm{N}, 2.71$. Found: $\mathrm{C}$, $37.30 ; \mathrm{H}, 2.96 ; \mathrm{N}, 2.65$.

- 4: Yield: 0.474 g, 0.946 mmol, $94.6 \%$, bright yellow solid. MS $(\mathrm{m} / \mathrm{z}): 280\left([\mathrm{M}]^{+}-5 \mathrm{CO}-\right.$ Cyclohexyl). $\quad{ }^{1} \mathrm{H}$ NMR $\left(\mathrm{CDCl}_{3}, \mathrm{ppm}\right)$ : Isomer $A: \delta 8.93(\mathrm{~s}(\mathrm{~b}), \mathrm{N} 1-\mathrm{H})$, 7.51 (d, H10, 1.4 Hz), 7.38 (dd, H8, 3.6, 0.5 Hz), 6.57 (dd, H9, 3.6, 0.5 Hz), 4.31-4.42 (m, H11), 1.12-2.15 (m, H12-H14); Isomer $B: \delta 8.13(\mathrm{~s}(\mathrm{~b}), \mathrm{N} 1-\mathrm{H}), 7.68(\mathrm{dd}$, H10, 1.8, $0.6 \mathrm{~Hz}$ ), 7.25 (dd, H8, 3.6, 0.6 Hz), 6.60 (dd, $\mathrm{H} 9,3.6,1.8 \mathrm{~Hz}), 4.09-4.22(\mathrm{~m}, \mathrm{H} 11), 1.12-2.15(\mathrm{~m}$, H12-H14).- ${ }^{13} \mathrm{C} \mathrm{NMR}\left(\mathrm{CDCl}_{3}, \mathrm{ppm}\right)$ : Isomer $A$ : $\delta 219.3$ (C6), $202.4\left(\mathrm{CO}_{\text {trans }}\right), 198.4\left(\mathrm{t}, \mathrm{CO}_{\text {cis }}, \mathrm{J}_{\mathrm{W}-\mathrm{C}}=126.9 \mathrm{~Hz}\right)$, 159.1 (C7), 144.1 (C10), 126.3 (C8), 113.7 (C9), 64.3 (C11), 33.1 (C12), 24.5 (C13), 25.3 (C14). Isomer $B: \delta$ 225.7 (C6), $202.8\left(\mathrm{CO}_{\text {trans }}\right), 199.1\left(\mathrm{t}, \mathrm{CO}_{\text {cis }}, \mathrm{J}_{\mathrm{W}-\mathrm{C}}=122.2\right.$ Hz), 157.6 (C7), 145.8 (C10), 126.4 (C8), 113.3 (C9), 61.1 (C11), 33.2 (C12), 24.3 (C13), 25.3 (C14).- IR $\left(\mathrm{KBr}, \mathrm{cm}^{-1}\right): v_{\mathrm{CO}}=2059(\mathrm{~m}), 1966(\mathrm{vw}), 1908(\mathrm{~s}), 1882$ (vs). Anal. Calcd for $\mathrm{C}_{16} \mathrm{H}_{15} \mathrm{NO}_{6} \mathrm{~W}: \mathrm{C}, 38.35 ; \mathrm{H}, 3.02$; N, 2.80. Found: C, 38.30; H, 2.98; N, 2.99.

\section{Aminolysis of complexes 1 and 2 with ethylene dia- mine}

- Ethylene diamine $(0.05 \mathrm{~mL}, 0.75 \mathrm{mmol})$ was dissolved in $10 \mathrm{~mL}$ of DCM, and complex $1(0.232 \mathrm{~g}, 0.50 \mathrm{mmol})$ or complex $2(0.224 \mathrm{~g}, 0.50 \mathrm{mmol})$, repectively, was added to the solution while maintaining vigorous stir- ring. Initially the reaction mixture was dark red, but gradually became bright yellow. The solvent was removed, yielding a bright yellow crystalline solid, $\mathbf{5}$ or $\mathbf{6}$, respectively.

- 5: Yield: 0.136 g, $0.284 \mathrm{mmol}, 56.9 \%$, bright yellow crystalline solid. - ${ }^{1} \mathrm{H}$ NMR $\left(\mathrm{CDCl}_{3}, \mathrm{ppm}\right): \delta 9.52$ (s(b), N1-H), 7.52 (dd, H10, 5.1, 1.2 Hz), 7.43 (dd, H8, 3.8, $1.2 \mathrm{~Hz}), 7.12$ (dd, H9, 5.1, 3.8 Hz), 3.94-3.98 (m, H11), 3.14-3.16 (m, H12), $1.72\left(\mathrm{~s}(\mathrm{~b}), \mathrm{N} 2-\mathrm{H}_{2}\right) .-{ }^{13} \mathrm{C} \mathrm{NMR}$ $\left(\mathrm{CDCl}_{3}, \mathrm{ppm}\right): \delta 237.6(\mathrm{C} 6), 202.7\left(\mathrm{CO}_{\text {trans }}\right), 198.5(\mathrm{t}$, $\left.\mathrm{CO}_{\text {cis }}, \mathrm{J}_{\mathrm{W}-\mathrm{C}}=127.3 \mathrm{~Hz}\right), 157.0(\mathrm{C} 7), 130.0(\mathrm{C} 10), 128.1$ (C8), 127.4 (C9), 55.9 (C11), 40.2 (C12). - IR (KBr, $\left.\mathrm{cm}^{-1}\right): v_{\mathrm{CO}}=2059(\mathrm{~m}), 1916(\mathrm{vs})$. Anal. Calcd for $\mathrm{C}_{12} \mathrm{H}_{10} \mathrm{~N}_{2} \mathrm{O}_{5} \mathrm{SW}$ : C, 30.14; H, 2.11; N, 5.86. Found: C, $30.30 ; \mathrm{H}, 1.98 ; \mathrm{N}, 5.99$.

- 6: Yield: $0.164 \mathrm{~g}, 0.355 \mathrm{mmol}, 70.8 \%$, bright yellow crystalline solid. MS $(\mathrm{m} / \mathrm{z}): 279\left([\mathrm{M}]^{+}-\mathrm{EtNH}_{2}-5 \mathrm{CO}\right)$. ${ }^{1} \mathrm{H}$ NMR $\left(\mathrm{CDCl}_{3}, \mathrm{ppm}\right): \delta 9.89(\mathrm{~s}(\mathrm{~b}), \mathrm{N} 1-\mathrm{H}), 7.54(\mathrm{~s}$, H8), 7.38 (s, H10), 6.56 (s, H9), 3.95 (m, H11), 3.15 (m, $\mathrm{H} 12), 1.70$ (s(b), N2-H $) .-{ }^{13} \mathrm{C} \mathrm{NMR}\left(\mathrm{CDCl}_{3}, \mathrm{ppm}\right): \delta$ 223.2 (C6), $202.3\left(\mathrm{CO}_{\text {trans })}, 198.6\left(\mathrm{t}, \mathrm{CO}_{\text {cis }}, \mathrm{J}_{\mathrm{W}-\mathrm{C}}=126.0\right.\right.$ $\mathrm{Hz}), 159.6$ (C7), 144.4 (C10), 125.7 (C8), 113.6 (C9), $55.8(\mathrm{C} 11), 40.6(\mathrm{C} 12)$. - IR $\left(\mathrm{KBr}, \mathrm{cm}^{-1}\right): v_{\mathrm{CO}}=2058$ (m), 1972 (vw), 1910 (s), 1916 (vs). Anal. Calcd for $\mathrm{C}_{12} \mathrm{H}_{10} \mathrm{~N}_{2} \mathrm{O}_{6} \mathrm{~W}: \mathrm{C}, 31.19 ; \mathrm{H}, 2.18 ; \mathrm{N}, 6.06$. Found: $\mathrm{C}$, $31.02 ; \mathrm{H}, 2.13 ; \mathrm{N}, 6.22$.

\section{Thermal reaction of complexes 1 and 2 with ethylene diamine}

- Ethylene diamine $(0.0763 \mathrm{~g}, 1.27 \mathrm{mmol})$ was dissolved in $30 \mathrm{~mL}$ of toluene and placed in a heated oil bath at $105^{\circ} \mathrm{C}$. Complex $1(0.465 \mathrm{~g}, 1.00 \mathrm{mmol})$ or complex 2 $(0.448 \mathrm{~g}, 1.00 \mathrm{mmol})$, respectively, was added to the solution, forming a dark red solution. The reaction mixture was allowed to reflux for $1 \frac{1 / 2}{2}$ hours, with stirring. The solution was dark orange-red and an orange precipitate formed. The reaction mixture was allowed to cool, while the precipitate was allowed to settle. The solvent was decanted and the resulting orange precipitate washed with cold hexane. This precipitate was found to be only mildly soluble in DCM. It was completely soluble in THF and acetonitrile.

- 7: Yield: $0.228 \mathrm{~g}, 0.507 \mathrm{mmol}, 50.7 \%$, bright orange solid. - ${ }^{1} \mathrm{H}$ NMR $\left(\mathrm{CD}_{3} \mathrm{CN}, \mathrm{ppm}\right): \delta 9.68$ (s(b), N1-H), 7.69 (dd, H10, 5.1, $1.2 \mathrm{~Hz}$ ), 7.49 (dd, H8, 3.8, $1.2 \mathrm{~Hz}$ ), 7.18 (dd, H9, 5.1, 3.8 Hz), 3.58-3.65 (m, H11), 2.662.76 (m, H12), 3.39 (s(b), N2-H $).-{ }^{13} \mathrm{C} \mathrm{NMR}\left(\mathrm{CD}_{3} \mathrm{CN}\right.$, ppm): $\delta 246.9$ (C6), 216.0 (CO1), 213.3 (CO3), 205.8 (CO2), 156.1 (C7), 132.7 (C10), 128.9 (C8), 126.7 (C9), $52.3(\mathrm{C} 11), 40.8(\mathrm{C} 12)$. - IR $\left(\mathrm{KBr}, \mathrm{cm}^{-1}\right): v_{\mathrm{CO}}=2008$ (s), 1943 (s), 1906 (s), 1858 (vs). Anal. Calcd for $\mathrm{C}_{11} \mathrm{H}_{10} \mathrm{~N}_{2} \mathrm{O}_{4} \mathrm{SW}$ : C, 29.35; H, 2.24; N, 6.22. Found: C, 29.44; H, 2.28; N, 6.15 .

- 8: Yield: $0.214 \mathrm{~g}, 0.49 \mathrm{mmol}, 49.3 \%$, bright orange solid. - ${ }^{1} \mathrm{H}$ NMR $\left(\mathrm{CD}_{3} \mathrm{CN}, \mathrm{ppm}\right): \delta 9.93$ (s(b), N1-H), 7.66 (dd, H10, 1.8, 0.5 Hz), 7.52 (dd, H8, 3.6, 0.6 Hz), 6.60 (dd, H9, 3.6, 1.8 Hz), 3.61-3.67 (m, H11), 2.66-2.73 (m, $\mathrm{H} 12), 3.36$ (s(b), N2-H2). ${ }^{13} \mathrm{C} \mathrm{NMR}\left(\mathrm{CD}_{3} \mathrm{CN}, \mathrm{ppm}\right): \delta$ 235.4 (C6), 215.8 (CO1), 214.0 (CO3), 206.0 (CO2), n.o. (C7), 145.9 (C10), 125.8 (C8), 114.4 (C9), 52.1 (C11), $41.2(\mathrm{C} 12)$. - IR (KBr, cm $\left.{ }^{-1}\right): v_{\mathrm{CO}}=2006(\mathrm{~s})$, 1934 (s), 1904 (s), 1862 (vs). Anal. Calcd for 
$\mathrm{C}_{11} \mathrm{H}_{10} \mathrm{~N}_{2} \mathrm{O}_{5} \mathrm{~W}$ : C, 30.44; H, 2.32; N, 6.45. Found: C, $30.30 ; \mathrm{H}, 2.38 ; \mathrm{N}, 6.39$.

\section{X-ray Crystallographic studies}

- Single crystal X-ray data for 1, 2 and $\mathbf{6}$ were collected at $150 \mathrm{~K}$ on a Bruker D8 Venture kappa geometry diffractometer, with duo I $\mu$ s sources, a Photon 100 CMOS detector and APEX $\mathrm{II}^{55}$ control software using Quazar multi-layer optics monochromated, Mo- $K \alpha$ radiation by means of a combination of $\phi$ and $\omega$ scans. Data for $\mathbf{3}$ were collected at 100(2) K and data for 4 were collected at 293(2) K, using a Bruker APEX DUO 4K-CCD diffractometer. Data reduction was performed using SAINT $+{ }^{55}$ and the intensities were corrected for absorption using SADABS. ${ }^{55}$ The structures were solved by intrinsic phasing using SHELXTS ${ }^{56}$ and refined by fullmatrix least squares using SHELXTL and SHELXL$2013 .{ }^{56}$ Data for 8 was collected at 180 (2) K on a Nonius Kappa CCD diffractometer, using graphite monochromated, Mo Ka radiation by means of phi and omega scans, and semi-empirical absorption corrections were based on equivalence. In the structure refinement all hydrogen atoms were added in calculated positions and treated as riding on the atom to which they are attached. All non-hydrogen atoms were refined with anisotropic displacement parameters, all isotropic displacement parameters for hydrogen atoms were calculated as $\mathrm{X} \times$ Ueq of the atom to which they are attached, $\mathrm{X}=1.5$ for the methyl hydrogens and 1.2 for all other hydrogens. Data collection, structure solution and refinement details are available in each CIF.

- Ortep drawings ${ }^{57}$ of the six structures are included in figures 4-9 with ADP's at the 50\% probability level. The crystal structures have been deposited at the Cambridge Crystallographic Data Centre and allocated the deposition numbers: CCDC 953184 (1), 953185 (2), 953187 (3), 953188 (4), 953190 (6), 953191 (8).

\section{Cyclic Voltammetry}

Cyclic voltammogram (CV), square-wave voltammetry (SW) and linear sweep voltammogram (LSV) measurements were performed on $0.0005 \mathrm{~mol} \mathrm{dm}^{-3}$ compound solutions in dry acetonitrile containing $0.1 \mathrm{~mol} \mathrm{dm}^{-3}$ tetra- $n$-butylammonium hexafluorophosphate, $\left(\left[{ }^{\mathrm{n}}\left(\mathrm{Bu}_{4}\right) \mathrm{N}\right]\left[\mathrm{PF}_{6}\right]\right)$, as supporting electrolyte and under a blanket of purified argon at $25^{\circ} \mathrm{C}$ utilizing a BAS 100B/W voltammograph. A three-electrode cell, with a glassy carbon (surface area $7.07 \times 10^{-6} \mathrm{~m}^{2}$ ) working electrode, Pt auxiliary electrode and a Ag wire reference electrode. ${ }^{58}$ All temperatures were kept constant to within $0.5^{\circ} \mathrm{C}$. Scan rates were $0.050-5.000 \mathrm{~V} \mathrm{~s}^{-1}$. Successive experiments under the same experimental conditions showed that all oxidation and formal reduction potentials were reproducible within $10 \mathrm{mV}$. All cited potentials were referenced against the $\mathrm{Fc} / \mathrm{Fc}^{+}$couple as suggested by IUPAC. ${ }^{59}$ Ferrocene exhibited a peak separation $\Delta E_{\mathrm{p}}=E_{\mathrm{pa}}-E_{\mathrm{pc}}=0.069 \mathrm{~V}$ and $i_{p c} / i_{p a}=1.00$ under our experimental conditions. $E_{\mathrm{pa}}\left(E_{\mathrm{pc}}\right)=$ anodic (cathodic) peak potential and $i_{p a}\left(i_{p c}\right)=$ anodic (cathodic) peak current. $E^{\circ}$ $\left(\mathrm{Fc} / \mathrm{Fc}^{+}\right)=0.66(5) \mathrm{V}$ vs SHE in $\left[{ }^{\mathrm{n}}\left(\mathrm{Bu}_{4}\right) \mathrm{N}\right]\left[\mathrm{PF}_{6}\right] / \mathrm{CH}_{3} \mathrm{CN} .{ }^{60}$ Ferrocene $(\mathrm{FcH})$ and decamethyl ferrocene $\left(\mathrm{FcH}^{*},-508 \mathrm{mV}\right.$ vs $\mathrm{FcH} / \mathrm{FcH}^{+}$) were used as internal standards. Electrochemical results obtained with or without ferrocene (or decamethyl ferrocene) as internal standard were the same.
- All density functional theory (DFT) calculations were performed with the hybrid functional $\mathrm{B}^{2} \mathrm{LYP}^{61,62}$ (and uB3LYP for radical cations or anions) as implemented in the Gaussian 09 program package. ${ }^{63}$ Geometries were optimized in gas phase with the triple- $\zeta$ basis set 6$311 \mathrm{G}(\mathrm{d}, \mathrm{p})$ on all atoms except tungsten, where def$\mathrm{SVP}^{64}$ was used (this level is denoted B3LYP/def2SVP). Results obtained by the triple- $\zeta$ basis set 6$311 \mathrm{G}(\mathrm{d}, \mathrm{p})$ on all atoms except tungsten, where LANL2DZ was used (corresponding to the Los Alamos Effective Core Potential plus $\mathrm{DZ}^{65}$ ), or by including solvation effects (IEFPCM model, using acetonitrile $(\varepsilon$ $=37.5$ ) as solvent) gave similar results, see supporting information.

-

\section{ASSOCIATED CONTENT}

\section{Supporting Information}

Cif files giving X-ray crystallographic data for complexes 1, 2, 3, 4, 6 and 8 . The optimized coordinates of the DFT calculations are given in the Supporting Information. The data are available free of charge via the Internet at http://pubs.acs.org.

\section{AUTHOR INFORMATION}

\section{Corresponding Authors}

*Marilé Landman Tel: ++27-12-4202527 Fax: ++27-12-4204687, email:marile.landman@up.ac.za

*Jeanet Conradie, Tel: ++27-51-4012194, Fax: ++27-514446384, email:conradj@ufs.ac.za

†These authors contributed equally.

\section{Notes}

The authors declare no competing financial interests.

\section{ACKNOWLEDGMENT}

This work has received support from the Norwegian Supercomputing Program (NOTUR) through a grant of computer time (Grant No. NN4654K) (JC), the South African National Research Foundation (JC) and the Central Research Fund of the University of the Free State, Bloemfontein (JC) and the University of Pretoria (ML and PHvR).

\section{REFERENCES}

(1) Mills, O.S.; Redhouse, A.D. Chem. Commun. 1966, 814

(2) Werner, H.; Rascher, H. Inorg. Chim. Acta 1968, 2, 181.

(3) Fischer, E.O.; Aumann, R. Chem. Ber. 1969, 102, 1495.

(4) De Frémont, P.; Marion, N.; Nolan, S.P. Coord. Chem. Rev. 2009 253,862 .

(5) Sierra, M.A.; Chem. Rev. 2000, 100, 3591.

(6) Fey, N.; Haddow, M.F.; Harvey, J.N.; Mcmullin, C.L.; Orpen, A.G. Dalton Trans. 2009, 8183.

(7) Dötz, K.H.; Angew. Chem. Int. Ed. Engl. 1984, 23, 587.

(8) Jimenez-Halla, J.O.C.; Solá, M.; Chem. Eur. J. 2009, 15, 12503.

(9) Kotha, S.; Dipak, M.K.; Tetrahedron 2012, 68, 397.

(10) Dötz, K.H.; Tomuschat, P. Chem. Soc. Rev. 1999, 28, 187.

(11) Andrada, D.M.; Jimenez-Halla, J.O.C.; Solà, M. J. Org. Chem. 2010, 75,5821 .

\section{DFT calculations}


(12) Heckl, B.; Werner, H.; Fischer, E.O. Angew. Chem. Int. Ed. Engl. 1968, $7,817$.

(13) Bernasconi, C.F.; Stronach, M.W. J. Am. Chem. Soc. 1993, 115, 1341 .

(14) Imwinkelried, R.; Hegedus, L.S. Organometallics 1988, 7, 702.

(15) Fischer, E.O.; Winkler, E.; Kreiter, C.G.; Huttner, G.; Krieg, B. Angew. Chem. Int. Ed. Engl. 1971, 10, 922.

(16) Maiorana, S.; Seneci, P.; Rossi, T.; Baldoli, C.; Ciraco, M.; de Magistris, E.; Licandro, E.; Papagni, A.; Provera, S. Tetrahedron Lett. 1999, 40, 3635.

(17) Sabaté, R.; Schick, U.; Moreto, J.M.; Ricart, S. Organometallics 1996, 15,3611 .

(18) Fernández, I.; Sierra, M.A.; Gomez-Gallego, M.; Mancheno, M.; Cossío, F.P. Angew. Chem. 2006, 118, 131.

(19) Metelkova, R.; Tobrman, T.; Kvapilova, H.; Hoskovcova, I.; Ludvik, J. Electrochim. Acta, 2012, 82, 470.

(20) Dötz, K.H.; Stendel, J.; Chem. Rev. 2009, 109, 3227.

(21) Wu, Y.-T.; Kurahashi, T.; de Meijere, A. J. Organomet. Chem. 2005, 690, 5900.

(22) Terblans, Y.M.; Roos, H.M.; Lotz, S. J. Organomet. Chem. 1998 $566,133$.

(23) Crause, C.; Görls, H.; Lotz, S. Dalton Trans. 2005, 1649.

(24) Landman, M.; Görls, H.; Lotz, S. J. Organomet. Chem. 2001, 617, 280 .

(25) Connor, J.A.; Jones, M. J. Chem. Soc. (A) 1971, 1974.

(26) Crause, C.; Synthesis and application of carbene complexes with heteroaromatic substituents, $\mathrm{PhD}$ thesis, University of Pretoria, 2004.

(27) (a) Ye, Q.; Wu, Q.; Zhao, H.; Song, Y-M.; Xiang Xue, Xiong, RG.; Pang, S-M.; Lee, G-H. J. Organomet. Chem. 2005, 690, 286. (b) Chapman,b J.; Kolawole, G.; Long, N.; White, A.J.P.; Williams, D.J.; O'Brien, P. S. Afr. J. Sci.(2005, 101, 454.

(28) Fischer, E.O.; Aumann, R. Angew. Chem. Int. Ed. Engl. 1967, 6, 879 .

(29) Moreto, J.M.; Ricart, S.; Dötz, K.H.; Molins, E. Organometallics 2001, 20, 62 .

(30) Hafner, A.; Hegedus, L.S.; de Weck, G.; Hawkins, B.; Dötz, K.H. J. Am. Chem. Soc. 1988, 110, 8413.

(31) Cardin, D.J.; Cetinkaya, B.; Lappert, M.F. Chem. Rev. 1972, 72, 545.

(32) Darensbourg, M.Y.; Darensbourg, D.J. Inorg. Chem. 1970, 9, 32.

(33) Connor, J.A.; Jones, M.; Randall, E.W.; Rosenberg, E. J. Chem. Soc. Dalton Trans. 1972, 2419.

(34) Lotz, S.; Landman, M.; Bezuidenhout, D.I.; Oliver, A.J.; Liles, D.C.; van Rooyen, P.H. J. Organomet. Chem. 2005, 690, 5929.

(35) Moser, E.; Fischer, E.O. J. Organomet. Chem. 1969, 16, 275.

(36) (a) Hafner, A.; Hegedus, L.S.; de Weck, G.; Hawkins, B.; Dötz, K.H. J. Chem. Soc., 1988, 110, 8413. (b) Cardin, D.J.; Cetinkaya, B.; Lappert, M.F. Chem. Rev., 1972, 72, 545. (c) Darensbourg, M.Y.; Darensbourg, D.J. Inorg. Chem., 1970, 9, 32.

(37) Streubel, R.; Priemer, S.; Jones, P.G. J. Organometal. Chem. 2001, 618, 423 .

(38) Arrieta, A.; Cossío, F.P.; Fernández, I.; Gomez-Gallego, M.; Lecea, B.; Mancheno, M.J.; Sierra, M.A. J. Am. Chem. Soc. 2000, 122, 11509 .

(39) Braterman, P.S. Metal carbonyl spectra, 1st ed.,Academic Press Inc.: London, 1975.

(40) Guns, M.F.; Claeys, E.G.; van der Kelen, G.P. J. Mol.Stuct. 1979, $54,101$.

(41) (a) Landman, M.; Ramontja, J.; van Staden, M.; Bezuidenhout, D.I.; van Rooyen, P.H.; Liles, D.C.; Lotz, S. Inorg. Chim. Acta, 2010, 363, (2010), 705. (b) Lotz, S.; Landman, M.; Görls, H.; Crause, C.; Nienaber, H.; Olivier, A.J. Z. Naturforsch. B 2007, 62, 419. (c) Lotz, S.; Crause, C.; Olivier, A.J.; Liles, D.C.; Görls, H.; Landman, M.; Bezuidenhout, D.I. Dalton Trans. 2009, 697.

(42) Thompson, S; Landman, M. J.Mol. Struct., submitted.
(43) Baldoli, C.; Cerea, P.; Falciola, L.; Giannini, C.; Licandro, Stefano Maiorana, E.; Mussini, P.; Perdicchia, P. J. Organomet. Chem. 2005, 690, 5777.

(44) Hoskovcová, I.; Roháčová, J.; Dvořák, D.; Tobrman, T.; Záliš, S.; Zvěřinová, R.; Ludvík, J. Electrochim. Acta 2010, 55, 8341.

(45)(a) Mabbott, M.A. J. Chem. Ed. 1983, 60, 697. (b) Kissinger, P.T.; Heineman, W.R. J. Chem. Ed. 1983, 60, 702 (c) Van Benschoten, J.J.; Lewis, J.Y.; Heineman, W.R.; Roston, D.A.; Kissinger, P.T. J. Chem. Ed. 1983, 60, 792 .

(46) Landman, M.; Renyuan, L.; van Rooyen, P.H.; Conradie, J. Electrochim. Acta 2013, under revision.

(47) Lloyd, M.K.; McCleverty, J.A. Orchard, D.G.; Connor, J.A.; Hall, M.B.; Hillier, I.H.; Jones, E.M.; McEwen, G.K. J. C. S. Dalton, 1973, 1743 .

(48) Kuhn, A.; Conradie, J. Electrochim. Acta 2010, 56, 257.

(49)(a) Sereda, G.; van Heukelom, J.; Koppang, M.; Ramreddy, S.; Collins, N. Beilstein Journal of Organic Chemistry 2006, 2, 26. (b) Rahman, A.; Qureshi, R.; Kiran, M.; Ansari, F.L. Turk. J. Chem., 2007, 31, 25. (c) Erasmus, J.J.C.; Conradie, J. Dalton Trans. 2013, 42, 8655. (d) Conradie, J. Electrochim. Acta; 2013, DOI: 10.1016/j.electacta.2013.01.021

(50) Schriver, D.F.; Drezdzon, M.A. The manipulation of Air-Sensitive Compounds; 2 nd; Wiley: New York, 1980.

(51) Spies, G.H.; Angelici, R.J. Organometallics 1987, 6, 1897.

(52) Meerwein, H. Org. Synth. 1966, 46, 113.

(53) Aoki, S.; Fujimura, T.; Nakamura, E. J. Am. Chem. Soc. 1992, $114,2985$.

(54) Crause, C.; Lotz, S. Dalton Trans. 2005, 9, 1649.

(55) APEX2 (including SAINT and SADABS); Bruker AXS Inc., Madison, WI, 2012.

(56) Sheldrick, G.M. Acta Crystallogr. A 2008, 64, 112

(57) Faruggia, L.J. J. Appl. Crystallogr., 1997, 30, 565.

(58) Sawyer, D.T.; Roberts (Jr), J.L. Experimental Electrochemistry for Chemists, Wiley, New York, 1974, 54.

(59) Gritzner, G.; Kuta, J. Pure Appl. Chem. 1984, 56, 461.

(60) Pombeiro, A.J.L. J. Organomet. Chem. 2005, 690, 6021.

(61) Becke, A.D. Phys. Rev. 1988, A38, 3098.

(62) Lee, C.; Yang, W.; Parr, R.G. Phys. Rev. 1988, B37, 785

(63) Gaussian 09, Revision C.01, Frisch, M.J.; Trucks, G.W.; Schlegel, H.B.; Scuseria, G.E.; Robb, M.A.; Cheeseman, J.R.; Scalmani, G.; Barone, V.; Mennucci, B.; Petersson, G.A.; Nakatsuji, H.; Caricato, M.; Li, X.; Hratchian, H.P.; Izmaylov, A.F.; Bloino, J.; Zheng, G.; Sonnenberg, J.L.; Hada, M.; Ehara, M.; Toyota, K.; Fukuda, R.; Hasegawa, J.; Ishida, M.; Nakajima, T.; Honda, Y.; Kitao, O.; Nakai, H.; Vreven, T.; Montgomery, Jr., J.A.; Peralta, J.E.; Ogliaro, F.; Bearpark, M.; Heyd, J.J.; Brothers, E.; Kudin, K.N.; Staroverov, V.N.; Keith, T.; Kobayashi, R.; Normand, J.; Raghavachari, K.; Rendell, A.; Burant, J.C.; Iyengar, S.S.; Tomasi, J.; Cossi, M.; Rega, N.; Millam, J.M.; Klene, M.; Knox, J.E.; Cross, J.B.; Bakken, V.; Adamo, C.; Jaramillo, J.; Gomperts, R.; Stratmann, R.E.; Yazyev, O.; Austin, A.J.; Cammi, R.; Pomelli, C.; Ochterski, J.W.; Martin, R.L.; Morokuma, K.; Zakrzewski, V.G.; Voth, G.A.; Salvador, P.; Dannenberg, J.J.; Dapprich, S.; Daniels, A.D.; Farkas, O.; Foresman, J.B.; Ortiz, J.V.; Cioslowski, J.; Fox, D.J. Gaussian, Inc., Wallingford CT, 2010 .

(64) Weigend, F.; Ahlrichs, R.; Phys. Chem. Chem. Phys. 2005, 7, 3297.

(65)(a) Dunning Jr., T.H.; Hay, P.J. Modern Theoretical Chemistry, Ed. H.F. Schaefer III, Vol. 3 Plenum, New York, 1976; (b) Hay, P.J.; Wadt, W.R. J. Chem. Phys. 1985, 82, 270. (c) Hay, P.J.; Wadt, W.R. J. Chem. Phys. 1985, 82, 284. (d) Hay, P.J.; Wadt, W.R. J. Chem. Phys. 1985, 82, 299. 